Check for updates

Cite this: Phys. Chem. Chem. Phys., 2017, 19, 27489

Received 31st July 2017 Accepted 18th September 2017 DOI: $10.1039 / c 7 c p 05185 a$ rsc.li/pccp

\section{The duality of UiO-67-Pt MOFs: connecting treatment conditions and encapsulated Pt species by operando XAS $\dagger$}

\author{
L. Braglia, (D)*ab E. Borfecchia, (D) a A. Martini, ${ }^{a}$ A. L. Bugaev, ${ }^{a b}$ A. V. Soldatov, ${ }^{b}$ \\ S. Øien-Ødegaard, ${ }^{C}$ B. T. Lønstad-Bleken, ${ }^{C}$ U. Olsbye, ${ }^{D}{ }^{c}$ K. P. Lillerud, ${ }^{c}$ \\ K. A. Lomachenko, (D) ${ }^{\text {bd }}$ G. Agostini, ${ }^{\text {de }}$ M. Manzoli (iD ${ }^{f}$ and C. Lamberti (iD $* b g$
}

\begin{abstract}
An X-ray absorption spectroscopy study of the UiO-67 Pt functionalized metal organic frameworks (MOFs) demonstrates that under appropriate conditions, at least two types of catalytically active sites can be formed in the cavities of the MOF: isolated Pt-complexes and Pt nanoparticles (Pt-NPs). Both pre-made linker synthesis (PMLS) and post-synthesis functionalization (PSF) methods were adopted. XAS was used to monitor the temperature-dependent behaviour of UiO-67-Pt while heating from RT to $623 \mathrm{~K}$, in different gas feeds (pure $\mathrm{He}, 3 \% \mathrm{H}_{2} / \mathrm{He}$ and $10 \% \mathrm{H}_{2} / \mathrm{He}$ ). We collected static in situ Pt $\mathrm{L}_{\text {III }}$ XANES and EXAFS spectra at room temperature (RT) before and after the thermal treatment, as well as spectra acquired under operando conditions upon heating. Under $10 \% \mathrm{H}_{2} / \mathrm{He}$ thermal treatment, we unambiguously detected Pt-NP formation which has been followed by a parametric EXAFS analysis of the data collected during temperature programmed $\mathrm{H}_{2}$-reduction (TPR), using the Einstein model to predict the temperature dependence of the Debye-Waller factors. Conversely, in pure He flow, the only significant change observed during TPR is the progressive decrease of the $\mathrm{Pt}-\mathrm{Cl}$ single scattering contribution, leading to the conclusion that the Pt grafted to the bpydc-linkers remains naked. Advanced EXAFS/TEM analysis allowed us to quantify the fraction of Pt in the form of Pt-NPs, values that have been quantitatively confirmed by linear combination analysis of the XANES spectra. In situ XANES/EXAFS study was supported by ex situ XRPD and BET analyses, confirming the framework stability and testifying a loss of the internal volume after TPR due to the formation of Pt-NPs insides the MOF pores, more relevant in the sample where smaller Pt-NPs were formed.
\end{abstract}

\section{Introduction}

In the last few decades, the discovery of new types of metal organic frameworks (MOFs) has increased exponentially. ${ }^{1-17}$ In particular, in the present work, we focused our attention on their employment as supports for active metal sites in heterogeneous catalysis. ${ }^{18-22}$ However, metal sites in most of the MOF structures show a maximum of one coordination vacancy (and only after removal of the solvent, see e.g. HKUST-1 ${ }^{23,24}$ and CPO- $27^{25-27}$ ), therefore limiting their application in catalysis, where at least two coordination vacancies are required. In this regard, the functionalization of MOF materials is one of the main challenges driving the MOF community, ${ }^{28-41}$ to make newer and newer structures, with specific functionalities.

Among the many classes of MOFs, the UiO-66/67/68 family ${ }^{42-52}$ shows an incredible thermal and chemical stability. The UiO-66/67/68 frameworks are obtained by connecting the 12-fold coordinated $\mathrm{Zr}_{6} \mathrm{O}_{4}(\mathrm{OH})_{4}$ inorganic cuboctahedron with organic linkers of increasing length, 1,4-benzene-dicarboxylate (bdc), 
4,4'-biphenyl-dicarboxylate (bpdc) or 4,4'-terphenyl-dicarboxylate (tpdc). ${ }^{42}$ Because of their high stability, this class of materials is an attractive candidate for a variety of applications in the fields of catalysis, ${ }^{53-61} \mathrm{H}_{2},{ }^{44} \mathrm{CH}_{4},{ }^{62,63}$ and $\mathrm{CO}_{2}{ }^{61,64,65}$ uptake, proton conduction, ${ }^{66,67}$ removal of air $^{68}$ and water ${ }^{69}$ contaminants, gas separation, ${ }^{70-72}$ sensor applications, ${ }^{73}$ and radioactive waste scavenging. ${ }^{74}$

Also in the case of UiO-66/67/68, functionalization has played an important role in enhancing the material potentialities. Among all, we mention functionalization by insertion of other metals in the inorganic cornerstone $\mathrm{M}_{x} \mathrm{Zr}_{6-x} \mathrm{O}_{4}(\mathrm{OH})_{4}(\mathrm{M}=\mathrm{Hf}, \mathrm{Ce}, \mathrm{Ti}) ;^{74-76}$ functionalization by controlled defect engineering (missing linkers, metal centers or inorganic cornerstones); ${ }^{46,49,50,53,54,64,77-80}$ bromo, nitro, and naphthalene functionalization of UiO-66/67; ${ }^{21,81-83}$ proline functionalization of UiO- $67 / 68 ;^{84}$ functionalization by use of biphenyl-, terphenyl-, and quaterphenyl-based linkers; ${ }^{85}$ and $\mathrm{N}$-quaternization of the pyridine sites of UiO- $67 .{ }^{65}$

In this respect, there are multiple choices of relatively easy ways to functionalize the linker of UiO-67 with metal sites by substituting a fraction of the standard bpdc linkers with a bipyridine-dicarboxylate (bpydc) linker, as described in the Experimental section. In such a way, $\mathrm{Fe}(\mathrm{II}),{ }^{86} \mathrm{Ni}(\mathrm{II}),{ }^{87} \mathrm{Cu}$ (II), ${ }^{88-92}$ $\mathrm{Ru}(\mathrm{II}),{ }^{93} \mathrm{Rh}(\mathrm{III}),{ }^{94,95} \operatorname{Pd}(\mathrm{II}),{ }^{96} \operatorname{Re}(\mathrm{I}),{ }^{93} \operatorname{Ir}(\mathrm{III}){ }^{93,95} \mathrm{Pt}(\mathrm{II}),{ }^{92,97-100}$ and $\mathrm{Pt}(\mathrm{IV})^{92,98,99}$ have already been successfully grafted to the two $\mathrm{N}$ atoms of the functionalized bpydc linker of different MOFs. In this paper, we present a study done on UiO-67 functionalized with Pt, a metal chosen for its extensive and interesting chemistry in catalysis. Indeed, Pt-based catalysts are used in a wide range of industrial applications, which include proton exchange in membrane fuel cells, ${ }^{101}$ industrial synthesis of nitric acid, ${ }^{102}$ oxidation of $\mathrm{CO}$ and $\mathrm{NO}_{x}$ in the exhaust gases from vehicles (Pt is one of the components of the catalytic converter), ${ }^{103,104}$ hydrogenation of nitro compounds to amines ${ }^{105}$ and the reaction from ketones to alcohols. ${ }^{106}$ In many of these reactions, a central role is covered by zero-valent Pt nanoparticles, usually supported on high surface area oxides, zeolites or carbons. In general, the catalytic activity per metal atom increases while decreasing the size of the metal particles, and therefore the development of an experimental procedure to lower the metal particles to nano-, subnano- and even single-atom size is a very attractive topic. ${ }^{107}$ Due to their extraordinarily high surface area and well-defined pore structure, MOFs can be used for the stabilization of metal nanoparticles with adaptable size and narrow size distribution. ${ }^{108,109}$ The important fact is that the embedded metal nanoparticles are still accessible for other reagents due to the high porosity of the MOF systems. Moreover, Na et al. ${ }^{110}$ have shown how Pt-NPs deposited on UiO-66 and UiO-67 or embedded in their cavities achieved different products and selectivity during the reaction with methylcyclopentane. In this study, we found out that tuning the $\mathrm{H}_{2}$ flow during the thermal treatment of UiO-67-Pt allows the nature of the encapsulated Pt-species to be tuned from isolated framework Pt(II) exhibiting two coordination vacancies (potentially interesting for $\mathrm{C}-\mathrm{H}$ bond activation $)^{111-116}$ to very small Pt-NPs hosted inside the MOF cavities, potentially interesting for hydrogenation reactions. ${ }^{117}$ In addition, we compared during the same treatment the behavior of UiO-67 functionalized with different Pt contents and two synthesis methods. The former involves premade linker synthesis (PMLS) in which $\mathrm{PtCl}_{2}\left(\mathrm{H}_{2}\right.$ bpydc) is used as an organic secondary building unit in the MOF synthesis, and the latter concerns post synthesis functionalization (PSF) where a platinum chloride solution is reacted with UiO-67 with open bpydc sites. ${ }^{98}$ We performed XAS spectroscopy for all the samples under in situ and operando conditions; by means of X-ray absorption spectroscopy near-edge structure (XANES) we monitored the oxidation state of Pt, and by analyzing the extended X-ray absorption fine structure (EXAFS) we observed the loss of $\mathrm{Cl}$ ligands during the thermal treatment and the formation of Pt-NPs, also confirmed by TEM measurements. Operando XANES experiments were supported by quasi simultaneous X-ray powder diffraction (XRPD) data collection testifying the resistance of the UiO-67 framework to the temperature programmed $\mathrm{H}_{2}$-reduction (TPR). In situ XANES/EXAFS studies were supported by ex situ XRPD and BET analyses. The former confirmed the framework stability while the latter testified a loss of the internal volume due to the formation of Pt-NPs insides the MOF pores.

In summary, herein we verify that Pt functionalized UiO-67 can lead to either bpydc-Pt(0) linkers, already studied by Øien et al., ${ }^{98}$ or to Pt nanoparticles (Pt-NPs), discussed in more detail in this work, and that the relative ratio between the two species can be tuned by controlling the activation conditions. Moreover, we compare the Pt-NP formation in Pt functionalized UiO-67 synthesized in different ways (PMLS or PSF) and with different Pt content (2.8 wt\% and $5.5 \mathrm{wt} \%)$.

\section{Experimental and methods}

\subsection{Materials synthesis}

We investigated a series of UiO-67 MOFs functionalized with Pt precursors. Pre-made linker synthesis (PMLS) and postsynthesis functionalization (PSF) were adopted for incorporating the Pt in the MOFs. ${ }^{98}$ The classic UiO-67 linker is the biphenyldicarboxylate (bpdc), ${ }^{44}$ while for grafting a transition metal to the MOF, Pt in this work, bipyridine (bpydc) linkers are employed. ${ }^{98}$ A detailed description of the synthesis and functionalization procedures follows.

Dimethylformamide (DMF) and demineralized $\mathrm{H}_{2} \mathrm{O}$ were added to a $250 \mathrm{~mL}$ Erlenmeyer flask with a magnetic stirring bar. $\mathrm{ZrCl}_{4}$ was slowly added to the solution, and completely dissolved. The slow addition was found to be particularly important, as it reacts exothermically with water. Then, benzoic acid, which is used as a modulator, ${ }^{118}$ was added and dissolved rapidly. The flask was then heated up to $110{ }^{\circ} \mathrm{C}$ while stirring. bpdc and bpydc linkers, or $\left(\mathrm{PtCl}_{2}\right)$ bpydc in the case of PMLS, were added simultaneously and gradually over a short period ( $~ 30$ seconds). A clear solution was obtained shortly after the addition. Afterwards, the stirring bar was removed and the flask was placed in an oven at $120{ }^{\circ} \mathrm{C}$ for two days. The solvent was removed using vacuum filtration and the residual white (or yellow) slurry was added back into the flask. About $50 \mathrm{~mL}$ of DMF was added to the flask 
Table 1 Abbreviation names and quantitative synthesis details for the samples

\begin{tabular}{|c|c|c|c|c|c|c|}
\hline \multirow[b]{2}{*}{ Chemical } & \multicolumn{2}{|c|}{ 5PMLS } & \multicolumn{2}{|c|}{ 10PMLS } & \multicolumn{2}{|c|}{ 10PSF } \\
\hline & Molar ratio & Mass (g) & Molar ratio & Mass (g) & Molar ratio & Mass (g) \\
\hline DMF & 300 & 94.4 & 300 & 94.4 & 300 & 94.4 \\
\hline $\mathrm{ZrCl}_{4}$ & 1 & 1.003 & 1 & 1.003 & 1 & 1.003 \\
\hline $\mathrm{H}_{2} \mathrm{O}$ & 3 & 0.23 & 3 & 0.23 & 3 & 0.23 \\
\hline Benzoic acid & 10 & 5.258 & 10 & 5.258 & 10 & 5.258 \\
\hline bpdc & 0.95 & 0.991 & 0.9 & 0.939 & 0.9 & 0.939 \\
\hline$\left(\mathrm{PtCl}_{2}\right)$ bpdc & 0.05 & 0.11 & 0.1 & 0.22 & - & - \\
\hline bpydc & - & - & - & - & 0.1 & 0.105 \\
\hline $\mathrm{K}_{2} \mathrm{PtCl}_{4}$ & - & - & - & - & 0.125 & 0.022 \\
\hline Yield (g) & & 1.15 & & 1.13 & & 1.18 \\
\hline Yield (\%) & & $73 \%$ & & $69 \%$ & & $72 \%$ \\
\hline Pt (wt\%) & 2.8 & & 5.5 & & 5.5 & \\
\hline
\end{tabular}

together with a stirring bar. The mixture was then stirred overnight to remove residual modulator (benzoic acid) at $40{ }^{\circ} \mathrm{C}$. The solvent was then removed by using a vacuum filtration setup. $50 \mathrm{~mL}$ of tetrahydrofuran (THF) was then added, and the mixture was stirred for two to three hours. THF was removed using a vacuum filtration setup and an extra $30 \mathrm{~mL}$ of THF was used to wash the powder on the filter. After filtrating, the powder was collected in an uncovered glass vial and put in an oven at $60{ }^{\circ} \mathrm{C}$ overnight to remove THF. The next day the temperature was increased to $200{ }^{\circ} \mathrm{C}$ to remove any residual high boiling point species, and the white (or yellow in the case of PMLS) powder was recovered after drying overnight.

For the PSF method, $1 \mathrm{~g}$ of the parent UiO-67-bpy (5-10\%) was mixed with $150 \mathrm{~mL}$ of DMF in a $250 \mathrm{~mL}$ round bottom flask. The mixture was then sonicated for one hour to disperse the UiO-67bpy powder. Afterwards, the round bottom flask was transferred to a hotplate with an oil bath. While stirring, $\mathrm{K}_{2} \mathrm{PtCl}_{4}$ (in a $25 \%$ molar excess with respect to the expected number of bpy sites) was slowly added. A reflux condenser was then connected to the flask and the mixture was heated up to $100{ }^{\circ} \mathrm{C}$ overnight. Within the first few hours the red crystals were observed to dissolve to give a red slurry. The next day, the MOF slurry had turned yellow, which indicated the coordination of platinum to the bpydc linker. The powder was collected using a vacuum filtration setup. Any remaining powder inside the flask was mixed with $30 \mathrm{~mL}$ of DMF and added to the filtration. The yellow slurry residual was transferred back into the round bottom flask and $50 \mathrm{~mL}$ of DMF was added. The mixture was then stirred for one hour under heating at $100{ }^{\circ} \mathrm{C}$ using the oil bath and reflux condenser again. The purpose of this washing step was to remove any excess $\mathrm{K}_{2} \mathrm{PtCl}_{4}$ that is not coordinated to the bpydc linker. Afterwards, the powder was collected again through a vacuum filtration setup. This washing step with hot DMF was repeated once. $50 \mathrm{~mL}$ of THF was then added, and the mixture was stirred for 15 minutes. THF was removed using a vacuum filtration setup and an extra $30 \mathrm{~mL}$ of THF was used to wash the powder on the filter. This step was repeated twice. After filtrating, the powder was collected in an uncovered glass vial and put in an oven at $60{ }^{\circ} \mathrm{C}$ overnight to remove THF. The temperature was increased to $150{ }^{\circ} \mathrm{C}$ and the yellow powder was recovered after drying overnight.
In particular, the samples investigated in this work are: UiO-67-5\% $\mathrm{H}_{2}$ bpydc- $\mathrm{PtCl}_{2}$ (PMLS) with 2.8 wt\% of Pt, UiO-67$10 \% \mathrm{H}_{2}$ bpydc- $\mathrm{PtCl}_{2}$ (PMLS) with $5.5 \mathrm{wt} \%$ of $\mathrm{Pt}$ and UiO-67$10 \% \mathrm{H}_{2}$ bpydc- $\mathrm{PtCl}_{2}$ (PSF) with $5.5 \mathrm{wt} \%$ of Pt (where $5 \%$ and $10 \%$ indicates the employed percentage of bpydc-linkers). For the sake of brevity, in the following we will use the abbreviated names listed in Table 1 for sample labelling (5PMLS, 10PMLS and 10PSF).

\subsection{Laboratory characterization set-ups: $\mathbf{N}_{2}$ adsorption isotherms, XRPD and TEM}

XRPD patterns were acquired using a Bruker D8 Discover diffractometer with $\mathrm{Cu} \mathrm{K}_{\alpha 1}$-radiation in reflection geometry. Nitrogen sorption measurements were performed on a BelSorp mini II instrument at $77 \mathrm{~K}$. All samples were measured in $9.001 \mathrm{~cm}^{3}$ glass cells. Prior to adsorption measurements the samples were pretreated (activated) under vacuum for $1 \mathrm{~h}$ at $80{ }^{\circ} \mathrm{C}$ and $2 \mathrm{~h}$ at $200{ }^{\circ} \mathrm{C}$. Brunauer-Emmett-Teller (BET) surface areas ${ }^{119}$ were calculated by fitting the isotherm data in the $p / p_{0}$ range $0-0.1$, meeting the established consistency criteria. ${ }^{120}$

Transmission electron microscopy (TEM) and high resolution TEM (HR-TEM) measurements were performed by using a Jeol 3010-UHR electron microscope operating at $300 \mathrm{kV}$, equipped with a $\mathrm{LaB}_{6}$ filament and with an Oxford Inca Energy TEM 300 EDS $\mathrm{X}$-ray analyzer by Oxford Link. Digital micrographs were acquired by means of a $(2 \mathrm{k} \times 2 \mathrm{k})$-pixel Gatan Ultrascan $1000 \mathrm{CCD}$ camera and processed by Gatan digital micrograph. Before the experiments, the reduced powders were milled in an agate mortar and deposited on a copper grid covered with a lacey carbon film. A statistical evaluation of the size of the Pt particles was carried out for each material. Histograms of the particle size distribution were obtained by considering at least $>1250$ nanoparticles on the collected images, and the mean particle diameter $\left(d_{\mathrm{m}}\right)$ was calculated as $d_{\mathrm{m}}=\sum d_{i} n_{i} / \sum n_{i}$, where $n_{i}$ is the number of particles of diameter $d_{i}$. The counting was carried out on electron micrographs acquired starting from $100000 \times$ magnification, where roundish Pt nanoparticles contrasted with respect to the support were detected.

\subsection{Operando XANES using a capillary reactor}

We performed operando XANES experiments at the BM01B beamline of the European Synchrotron Radiation Facility 
(ESRF, Grenoble, France, now moved to port BM31) 121,122 aiming to monitor the dual behavior of UiO-67 Pt functionalized MOFs upon thermal treatment from room temperature (RT) to $623 \mathrm{~K}$ and in different gas feeds $\left(0,3\right.$ and $\left.10 \% \mathrm{H}_{2} / \mathrm{He}\right)$ and to simultaneously check the structural stability of the UiO-67-Pt framework by XRPD. The beamline allows a rapid (about $30 \mathrm{~s}$ ) plug and play switch between X-ray absorption and X-ray diffraction setups, allowing both EXAFS and XRPD to be performed under exactly the same sample conditions. ${ }^{123}$

The operation energy at the ESRF was $6 \mathrm{GeV}$ with ring current ranging from 200 to $160 \mathrm{~mA}$ (and a lifetime of about $50 \mathrm{~h}$ ). The white beam, coming from the bending magnet, was monochromatized by a water-cooled double crystal Si(111) monochromator and shaped by a horizontal slit according to the length of the catalytic bed and detuned to avoid the third harmonic contribution. ${ }^{124}$ We worked in transmission mode at Pt $\mathrm{L}_{\mathrm{III}}$-edge $(11564 \mathrm{eV})$. We employed $30 \mathrm{~cm}$-ionization chambers to measure the incident, $I_{0}$, and transmitted, $I_{1}$, intensities, with $\mathrm{N}_{2}$ and $\mathrm{Ar}$ gases to guarantee $12 \%$ and $75 \%$ of absorption, respectively. The intensity $I_{2}$ transmitted by Pt reference foil located after the second ionization chamber was measured simultaneously using a third ionization chamber, and the resulting spectra were employed for energy alignment. ${ }^{124,125}$

X-ray powder diffraction was measured using $\lambda=0.51353(1) \AA$ radiation, selected by a $\mathrm{Si}(111)$ channel-cut monochromator. A CMOS-Dexela 2D detector was used which covered the $2 \theta$ range up to $32^{\circ}\left(d_{\text {min }}=0.93 \AA\right)$; the values below $4^{\circ}$ were not used in the refinement because the scattered intensity was affected by the beam-stop. The $\lambda$ value, the sample to detector distance and the detector tilts have been optimized by Rietveld refinement of NIST $\mathrm{LaB}_{6}$ and Si samples and kept fixed in the refinement of the UiO-67 patterns. For better statistics 20 diffraction images and 20 dark images (without X-ray beam) with an acquisition time of 1 second were collected at each of the external conditions. 2D XRPD patterns were processed by PyFAI $^{126}$ software which executes fast averaging, background subtraction and integration of images to obtain $I(2 \theta)$ patterns. Rietveld refinement was performed in Jana2006 code. $^{127}$

The as-prepared powdered MOF samples were packed into $1.5 \mathrm{~mm}$ quartz glass capillaries with quartz wool supporting both sides of the bed and additional tubing was accommodated to control the gas stream. The capillary diameter was optimized for XRPD, resulting in an edge jump at the Pt $\mathrm{L}_{\mathrm{III}}$-edge of $\Delta \mu x=0.08$ only, still allowing good quality XANES spectra to be obtained. The catalytic bed was packed to be about $5 \mathrm{~mm}$ long, which resulted in a sample mass of $c a .3 \mathrm{mg}$. An electronic flow meter was used to adjust the flow through the bed in order to have typically $1 \mathrm{~mL} \mathrm{~min}^{-1}$ for each $2 \mathrm{mg}$ of catalyst. The gas flow system (mass flow controller, valves) was driven and monitored remotely from the control room.

\subsection{In situ static XANES and EXAFS experiments before and after TPR using a cell for pelletized samples}

Based on the results obtained in the experiments at the BM01B beamline, we repeated the temperature-programmed reduction (TPR) in the RT-623 $\mathrm{K}$ range in $10 \% \mathrm{H}_{2}$ for the whole series of samples, using a different ad hoc cell designed for high-quality EXAFS data collection on pelletized samples, ${ }^{128}$ see Fig. S8 of the $\mathrm{ESI}, \dagger$ for a photographic description of the set-up.

We collected the data at the I811 beamline in Max Lab II (Lund, Sweden), ${ }^{129,130}$ operating at $1.5 \mathrm{GeV}$ with a current ranging from 250 and $100 \mathrm{~mA}$. A liquid He-cooled superconducting wiggler was employed to produce the white beam, and subsequently monochromatized by a horizontally sagittally focused double-crystal $\mathrm{Si}(111)$ monochromator, detuned to $20 \%$ to minimize the third harmonic at around $35 \mathrm{keV} .^{124}$ We performed the experiment in transmission mode at the Pt $\mathrm{L}_{\mathrm{III}}$-edge; the $I_{0}$ and $I_{1}$ were measured by $30 \mathrm{~cm}$-ionization chambers using a mixture of $\mathrm{Ar}$ and $\mathrm{N}_{2}$ gases to guarantee an absorption of $12 \%$ and $75 \%$, respectively. We acquired three spectra for each static condition of the sample: in He at RT, at

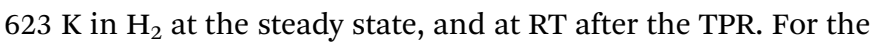
static measurements, the spectra were collected in quick-EXAFS mode $^{131}$ covering the energy range from $-200 \mathrm{eV}$ to $1680 \mathrm{eV}$ from the absorption edge in $600 \mathrm{~s}$ at constant angular speed. The extraction of the $\chi(k)$ was performed with the Athena code. ${ }^{132}$ The Artemis code ${ }^{132}$ was used to analyze the EXAFS spectra at RT before and after the TPR. The averaged $k^{2} \chi(k)$ functions were Fourier transformed (FT) in the $\Delta k=3.1-17.0 \AA^{-1}$ interval. The fits were performed on the averaged spectra ${ }^{133}$ in $R$-space in the $\Delta R=1.0-4.8 \AA$ range $(2 \Delta k \Delta R / \pi>33)$. The employed scattering paths were calculated with FEFF6 code ${ }^{134}$ using the [bpydc- $\mathrm{PtCl}_{2}$ ] DFT-optimized structure of the MOF-linker, previously reported by Borfecchia et al. ${ }^{99}$ Overall, the analysis confirmed the EXAFS results reported in our previous work. ${ }^{98}$ After the thermal treatment, apart from the [bpydc-PtCl $\left.{ }_{2}\right]$ input structure, we introduced in the EXAFS fit also the paths related with the Pt metal component, fundamental for fitting the contributions associated to the Pt-NPs.

\subsection{Operando TPR-EXAFS experiments using a cell for pelletized samples}

Operando temperature programmed $\mathrm{H}_{2}$-reduction (TPR) was done fluxing $10 \% \mathrm{H}_{2}$ in He with a flow of $100 \mathrm{~mL} \mathrm{~min}^{-1}$ inside the cell and increasing the temperature by $5 \mathrm{~K} \mathrm{~min}^{-1}$ until $623 \mathrm{~K}$. Each quick-EXAFS spectrum ranges from -200 to $1210 \mathrm{eV}$ from the edge with a total acquisition time of $360 \mathrm{~s}$, giving a temperature-resolution of the experiment of $\Delta T=30 \mathrm{~K}$. We acquired a series of EXAFS spectra from RT to $623 \mathrm{~K}$ and waited at $623 \mathrm{~K}$ until there were no further changes in the XAS features. Athena $\operatorname{code}^{132}$ was also used for the extraction of the $k^{2} \chi(k)$ functions of the spectra collected during the TPR experiments. Parametric EXAFS data analysis on the whole series of spectra was performed using the IFEFFIT code. ${ }^{135}$ Extracted $k^{2} \chi(k)$ functions were Fourier transformed in the $\Delta k=3.2-13.4 \AA^{-1}$ interval. The fits were performed in $R$-space in the $\Delta R=1.0-3.1 \AA$ range (number of independent points: $2 \Delta k \Delta R / \pi>13$ ). As the heating ramp of the TPR was $5 \mathrm{~K} \mathrm{~min}^{-1}$, EXAFS spectra were recorded with a temperature resolution of $30 \mathrm{~K}$. We used the same phase and amplitude functions employed to model the $\mathrm{Pt}-\mathrm{N}, \mathrm{Pt}-\mathrm{Cl}$ (for bpydc-PtCl ${ }_{2}$ linker) ${ }^{98,99}$ and the Pt-Pt (for Pt metal foil) single scattering (SS) paths in the analysis of the 
static EXAFS spectra. The main purpose of the TPR-EXAFS experiment was to monitor when and how the Pt-NPs were formed. The analysis of operando EXAFS during TPR is entangled by the presence of three SS paths related with at least two different Pt-species (framework bpydc-PtCl ${ }_{2}$ and Pt-NPs) but mostly by the strong correlation between coordination numbers $\left(N_{\mathrm{N}}, N_{\mathrm{Cl}}\right.$ and $N_{\mathrm{Pt}}$ ) and the corresponding Debye-Waller (DW) factors of $\mathrm{N}, \mathrm{Cl}$ and $\mathrm{Pt}$ atoms $\left({\sigma_{\mathrm{N}}}^{2},{\sigma_{\mathrm{Cl}}}^{2}\right.$ and ${\sigma_{\mathrm{Pt}}}^{2})$. DW factors, by definition, depend on the temperature, ${ }^{136}$ thus in a temperature-dependent experiment they are not constant. Hence, we adopted the Einstein model $^{137}$ to predict this dependence in the temperaturedependent EXAFS spectra. ${ }^{98,138-146}$ The details of the strategy for TPR-EXAFS analysis are described step by step in the following, distinguishing four subsequent refinement steps.

2.5.1. First refinement step. In this first step, considered as a preliminary consistency test, each EXAFS spectrum of the temperature-dependent series has been analyzed independently from the others. We refined the ${\sigma_{\mathrm{N}}}^{2},{\sigma_{\mathrm{Cl}}}^{2}$ and ${\sigma_{\mathrm{Pt}}}^{2}$ parameters and one independent $\Delta E$ common to both $\mathrm{Pt}-\mathrm{N}$ and $\mathrm{Pt}-\mathrm{Cl}$ paths (with the energy shift of the Pt-Pt paths, $\Delta E_{\text {metal }}$, constrained to $\Delta E_{\text {metal }}=\Delta E-2.7 \mathrm{eV}$, from the refinement of the Pt metal foil (see Fig. S5 and Table S1 of the ESI $\dagger$ ) and of the $\mathrm{PtCl}_{2}\left(\mathrm{H}_{2}\right.$ bpydc) linker, see Table 3). Conversely, the $S_{0}{ }^{2}$ of the two phases and the three bond distances $\left(R_{\mathrm{Pt}-\mathrm{N}}, R_{\mathrm{Pt}-\mathrm{Cl}}\right.$ and $\left.R_{\mathrm{Pt}-\mathrm{N}}\right)$ have been fixed to the values obtained in the refinement of the EXAFS spectrum collected under static conditions at RT in a longer $k$-range. The $N_{\mathrm{N}}, N_{\mathrm{Cl}}$ and $N_{\mathrm{Pt}}$ were refined for all data sets. Within the experimental incertitude, a constant value of around 2 was observed for both $N_{\mathrm{N}}$ and $N_{\mathrm{Cl}}$ along the whole heating step until $623 \mathrm{~K}$; for all these data $N_{\mathrm{Pt}}$ resulted in a non-physical trend jumping from positive to negative values (compatible with zero within the error). During the isotherm at $623 \mathrm{~K}$ a significant decay of both $N_{\mathrm{N}}$ and $N_{\mathrm{Cl}}$ is observed, accompanied by a parallel increase of $N_{\mathrm{Pt}}$, following a meaningful trend. As it can be appreciated in Fig. S1a-f of the ESI, $\dagger$ all refined parameters are subjected to large relative errors caused by a significant number of variables that correlate.

2.5.2. Second refinement step. To better appreciate temperature where the model adopted is not any more able to reproduce experimental data, Pt-Pt SS (not needed in the first part of the temperature ramp) was excluded and coordination numbers $\left(N_{\mathrm{N}}\right.$ and $\left.N_{\mathrm{Cl}}\right)$ were both imposed equal to two to avoid the correlation with the $\sigma_{\mathrm{N}}{ }^{2}$ and $\sigma_{\mathrm{Cl}}^{2}$ parameters. Therefore, we constrained our fitting model to only account for the presence of stable bpydc- $\mathrm{PtCl}_{2}$ linkers, during the whole thermal treatment. Afterwards, by plotting ${\sigma_{\mathrm{N}}}^{2}$ and ${\sigma_{\mathrm{Cl}}}^{2}$ as a function of time during TPR, see Fig. S1g-i, ESI, $\dagger$ we identified the temperature $\left(T_{\mathrm{I}}\right)$ when the DW factors begin to be unphysical and unstable. In the temperature interval between RT and $T_{\mathrm{I}}$, both $\sigma_{\mathrm{N}}{ }^{2}$ and $\sigma_{\mathrm{Cl}}^{2}$ values increase linearly with $T$, as expected from the Debye or Einstein models, ${ }^{140,145,147-149}$ for temperature considerably lower than that needed to break the bond. This linear behaviour guarantees that all $\mathrm{Pt}$ sites are in the form of undamaged bpydc- $\mathrm{PtCl}_{2}$ linkers.

2.5.3. Third refinement step. Considering the subset of spectra belonging to the linear region mentioned above, we have
Table 2 Summary of the Einstein temperatures $\theta_{\mathrm{E}}$ obtained for both Pt-N and $\mathrm{Pt}-\mathrm{Cl}$ bonds in the TPR-EXAFS experiments

\begin{tabular}{lll}
\hline Sample & $\Theta_{\mathrm{E}}(\mathrm{Pt}-\mathrm{N})(\mathrm{K})$ & $\Theta_{\mathrm{E}}(\mathrm{Pt}-\mathrm{Cl})(\mathrm{K})$ \\
\hline 5PMLS & $865 \pm 57$ & $511 \pm 13$ \\
10PMLS & $783 \pm 46$ & $458 \pm 10$ \\
10PSF & $691 \pm 35$ & $383 \pm 8$
\end{tabular}

then performed a parametric refinement, commonly adopted in XRPD Rietveld refinements, ${ }^{150,151}$ of the TPR-EXAFS spectra implementing the Einstein model for describing the temperature dependence of the ${\sigma_{\mathrm{N}}}^{2}$ and ${\sigma_{\mathrm{Cl}}}^{2}$ factors. The assumption in the Einstein model is that all atoms oscillate independently at the same single frequency called the Einstein frequency $\left(\omega_{\mathrm{E}}\right)$. The model assumes that both $\mathrm{Pt}-\mathrm{N}$ (or Pt-Cl) bonds behave as a quantum harmonic oscillator of mass equal to the reduced mass of the atomic pair $(M=13.070$ and 30.004 amu for the Pt-N and $\mathrm{Pt}-\mathrm{Cl}$ pairs, respectively). The behaviour of $\sigma^{2}(T)$ is determined only by the $\omega_{\mathrm{E}}$ parameter, according to the equation:

$$
\sigma^{2}(T)=\frac{\hbar}{2 M \omega_{\mathrm{E}}} \operatorname{coth}\left[\frac{\hbar \omega_{\mathrm{E}}}{2 k_{\mathrm{B}} T}\right]=\frac{\hbar^{2}}{2 M k_{\mathrm{B}} \Theta_{\mathrm{E}}} \operatorname{coth}\left[\frac{\Theta_{\mathrm{E}}}{2 T}\right] .
$$

The Einstein temperature $\Theta_{\mathrm{E}}$ of the Pt-N (or Pt-Cl) bond is related to the Einstein frequency by the relationship: $\hbar \omega_{\mathrm{E}}=$ $k_{\mathrm{B}} \Theta_{\mathrm{E}}$, where $\hbar=1.055 \times 10^{-34} \mathrm{~J} \mathrm{~s}$ is the reduced Planck constant and $k_{\mathrm{B}}=1.38 \times 10^{-23} \mathrm{~J} \mathrm{~K}^{-1}$ is the Boltzmann constant. The $N_{\mathrm{N}}$ and $N_{\mathrm{Cl}}$ were set to 2 because in the linear region we assumed only the presence of the bpydc- $\mathrm{PtCl}_{2}$ linker, as already verified in the first and second refinement steps. In this way, we obtained the Einstein temperatures for $\mathrm{Pt}-\mathrm{N}$ and $\mathrm{Pt}-\mathrm{Cl}$ that are reported in Table 2.

2.5.4. Fourth, and final, refinement step. In the fourth refinement, the $\mathrm{Pt}-\mathrm{Pt} \mathrm{SS}$ path was considered again, optimizing the $N_{\mathrm{Pt}}$ and the $\sigma_{\mathrm{Pt}}{ }^{2}$ parameters. As already done in the first refinement, $\Delta E_{\text {metal }}$ was constrained to the $\Delta E$ of the $\mathrm{Pt}$ (II) species in bpydc-PtCl ${ }_{2}$, according to the equation: $\Delta E_{\text {metal }}=\Delta E-2.7 \mathrm{eV}$. Then the whole series of EXAFS spectra were analyzed optimizing the coordination numbers $\left(N_{\mathrm{N}}, N_{\mathrm{Cl}}\right)$, with the two Debye-Waller factors $\left({\sigma_{\mathrm{N}}}^{2}\right.$ and ${\sigma_{\mathrm{Cl}}}^{2})$ fixed to the value obtained from eqn (1) and from the $\theta_{\mathrm{E}}$ parameters determined in the third refinement step, see Table 2 .

\section{Results and discussion}

\subsection{Determination of the Pt local environment in as-prepared UiO-67-Pt by static EXAFS}

According to our previous study, ${ }^{98}$ the EXAFS spectra of the three as-prepared samples were analysed using the $\left[\mathrm{PtCl}_{2}\left(\mathrm{H}_{2}\right.\right.$ bpydc)] optimized model, whose structure is reported in the inset of Fig. 1a. This structure consists of the Pt atom in square-planar coordination with two $\mathrm{N}$ atoms of the bpydc-linker and two $\mathrm{Cl}$ atoms. Parts (a) and (b) of Fig. 1 report the moduli and imaginary parts of the $k^{2}$-weighted, phase uncorrected, FT of the experimental EXAFS spectra of 5PMLS, 10PMLS and 10PSF samples. For comparison, Fig. 1 reports also the corresponding spectra for the $\mathrm{PtCl}_{2}\left(\mathrm{H}_{2}\right.$ bpydc) linker (grey curve) as a reference. All moduli 


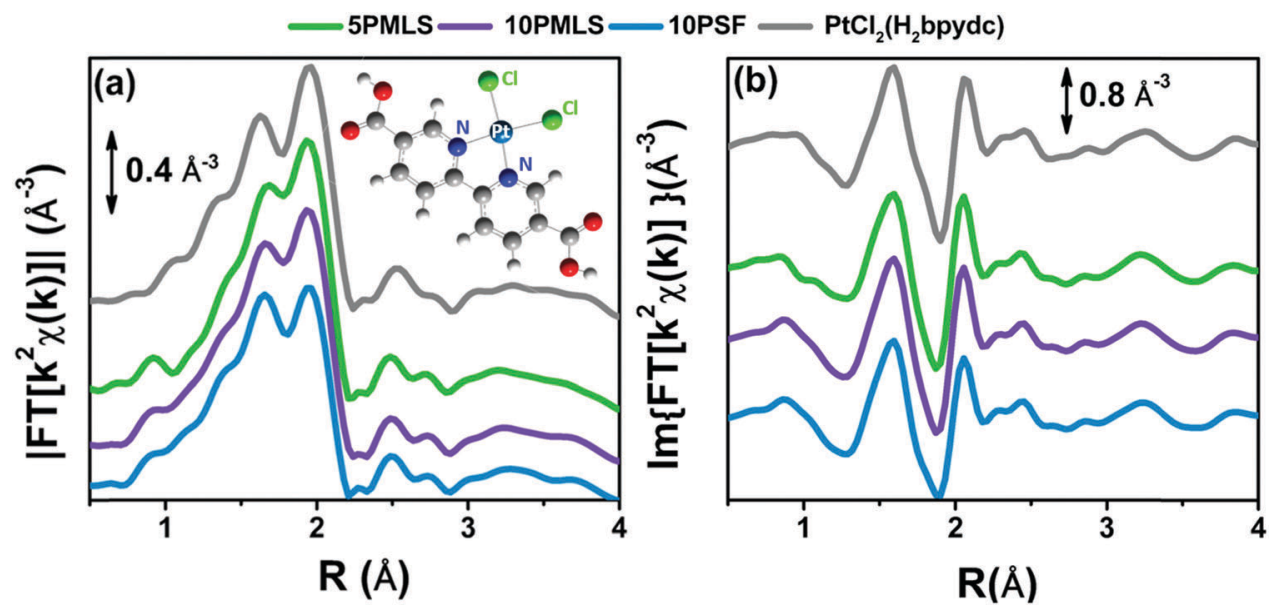

Fig. $1 k^{2}$-weighted, phase uncorrected, modulus (a) and imaginary part (b) of the experimental FT EXAFS spectra for 5PMLS (green), 10PMLS (violet) and 10PSF (cyan) in the as-prepared state at RT in air and $\mathrm{PtCl}_{2}\left(\mathrm{H}_{2}\right.$ bpydc) (grey) as a reference. Spectra were vertically shifted for clarity. In the inset in part (a) the $\left[\mathrm{PtCl}_{2}\left(\mathrm{H}_{2}\right.\right.$ bpydc) $]$ model is also reported, with $\mathrm{Pt}$ atoms in cyan, $\mathrm{N}$ atoms in blue, $\mathrm{Cl}$ atoms in green, $\mathrm{C}$ atoms in grey, $\mathrm{O}$ atoms in red and $\mathrm{H}$ atoms in white.

of FTs are characterized by two defined peaks at $1.67 \AA$ and at $1.94 \AA$ due to the first shell SS contributions from $\mathrm{N}$ and $\mathrm{Cl}$ atoms, respectively, followed by a complex structure in the 2.3-4.0 $\AA$ range due to a large number of SS and multiple scattering (MS) paths involving $\mathrm{N}$ and $\mathrm{C}$ atoms of the linker.

The position and the intensity of the EXAFS features for the samples synthesized by the PMLS method are the same as that of the linker, while the 10PSF presents a slightly lower intensity for the two peaks at $1.67 \AA$ and at $1.94 \AA$, as better appreciated in Fig. S2b and c, ESI, $\dagger$ where the curves of the different samples are reported without a vertical shift. The positions of the signals of $\mathrm{N}$ and $\mathrm{Cl}$ in the modulus of FT (see Fig. 1a and Fig. S2b, ESI $\dagger$ ) are partially overlapped, and thus it is difficult to distinguish which atomic species is responsible for the decrease of intensity. Instead, in the imaginary part of FT (see Fig. 1b and Fig. S2c, ESI $\dagger$ ) the differences between the two atomic contributions can be resolved more easily, highlighting an average lack of $\mathrm{Cl}$ ligands in PSF MOFs with respect to PMLS samples and with respect to the $\mathrm{PtCl}_{2}\left(\mathrm{H}_{2} \mathrm{bpydc}\right)$ linker (grey curve). In general, the lower signal in the FT could be interpreted also with a higher degree of inhomogeneity in the PSF sample. However, this alternative hypothesis can be ruled out looking at the data in $k$-space (Fig. S2a, ESI $\dagger$ ) where no particular dumping is observed in the high $k$-region for the spectrum of the 10PSF sample. This observation, joined with the fact that the high $R$-region of the FT of sample 10PSF corresponds to that of the $\operatorname{PtCl}_{2}\left(\mathrm{H}_{2} \mathrm{bpydc}\right)$ linker, allows us to conclude a full grafting of the $\mathrm{Pt}(\mathrm{II})$ species to the framework sites, with a lower coordination number of $\mathrm{Cl}$ in 10PSF. These qualitative insights were confirmed by EXAFS fits on the whole sample series. The fits were performed by guessing a passive amplitude reduction factor $S_{0}{ }^{2}$ common for all three MOF samples, for a more robust identification of slight differences in the average Pt coordination environment as a function of preparation protocol/Pt-loading. The optimized value $\left(S_{0}{ }^{2}=0.94 \pm 0.04\right)$ agrees well with the corresponding value optimized for the $\mathrm{PtCl}_{2}\left(\mathrm{H}_{2}\right.$ bpydc) linker $\left({S_{0}}^{2}=0.93 \pm 0.05\right)$, see Table 3. The numerous SS and MS paths of the $\mathrm{C}$ atoms in the bpydc-linker were considered using a "collective" parametrization strategy for the whole bpydc unit. ${ }^{24,25,91,152-154}$ In particular, these paths were modelled using an isotropic global contraction/expansion factor $\alpha_{\mathrm{bpydc}}$ and a DW factor $\sigma_{\text {bpydc }}{ }^{2}$ increasing as the square root of the effective distance $R_{\mathrm{eff}, i}\left(\Delta R_{\mathrm{bpydc}, i}=\alpha_{\mathrm{bpydc}} R_{\mathrm{eff}, i}, \sigma_{\mathrm{bpydc}, i}{ }^{2}=\sigma_{\mathrm{bpydc}}{ }^{2}\left(R_{\mathrm{eff}, i} / R_{\mathrm{N}}\right)^{1 / 2}\right)$, where $R_{\mathrm{eff}, i}$ corresponds to the interatomic distances for the SS contributions and to half of the overall scattering path for the MS ones and $R_{\mathrm{N}}=2.00 \AA$ A. This approach allows the optimization of only two parameters: $\alpha_{\text {bpydc }}$ and $\sigma_{\text {bpydc }}{ }^{2}$, with the obvious benefit of keeping the correlations among the optimized parameters as low as possible. ${ }^{24,25,91,152-154}$ All the parameters were guessed and we obtained meaningful results with $S_{0}{ }^{2}$ close to unity (0.94), and correlations among parameters below 0.8 in modulus. For both 5PMLS and 10PMLS samples, the coordination numbers of all paths have been fixed to the stoichiometric values of the model in the inset of Fig. 1a. All obtained values are fully comparable with those obtained on the $\mathrm{PtCl}_{2}\left(\mathrm{H}_{2}\right.$ bpydc) linker, with the only exception of a slightly shortened (by $0.025 \pm 0.006 \AA$ A $)$ Pt-Cl distance. For the 10PSF sample, we fixed $\sigma_{\mathrm{Cl}}^{2}$ to the average value obtained from the two previous fits $\left(\sigma_{\mathrm{Cl}}{ }^{2}=0.0027 \AA^{2}\right)$ and we optimized $N_{\mathrm{Cl}}$. Table 3 reports the parameters optimized in this refinement procedure.

The EXAFS analysis confirms the satisfactory synthesis for all the investigated samples (5PMLS, 10PMLS and 10PSF); indeed the Pt atom has been successfully grafted to the bpydc-linker. For both 5PMLS and 10PMLS samples, Pt(II) ions are coordinated to two $\mathrm{Cl}$ ligands, while for the 10PSF samples, around $30 \%$ of the $\mathrm{Pt}(\mathrm{II})$ species have lost one chlorine ligand in the post synthesis functionalization approach. We can speculate that the coordination vacancy left by such $\mathrm{Cl}$ species may be replaced by $\mathrm{H}$ species, which are not visible by EXAFS.

Fig. 2 shows the experimental modulus and imaginary part of the $k^{2}$-weighted, phase uncorrected, FT of the EXAFS spectra for the as prepared 5PMLS (parts a and b), 10PMLS (parts $\mathrm{c}$ and d) 
Table 3 Best-fit values of the parameters optimized in the EXAFS fits for the three samples (5PMLS, 10PMLS and 10PSF) in the as-prepared state and for the $\mathrm{PtCl}_{2}\left(\mathrm{H}_{2} \mathrm{bpydc}\right)$ linker model compound. The fits were performed in the $R$ space over the (1.0-4.8) $\AA$ interval on the $k^{2} \chi(k)$ function Fourier-transformed in the (3.1-17.0) $\AA^{-1} k$-space interval. Fixed parameters are reported as bold numbers without the corresponding errors. The quality of the fits can be appreciated in Fig. 2

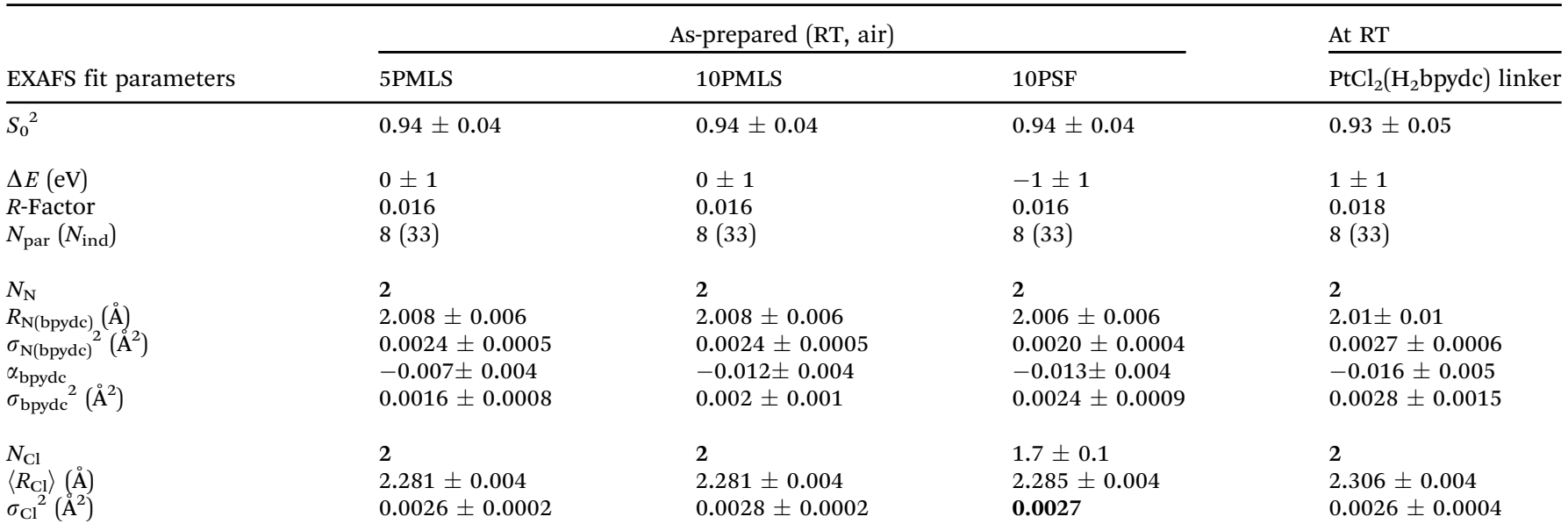

and 10PSF (parts e and f), open black circles, compared with the corresponding best fit curves, red lines. The figure also reports the SS contributions of the $\mathrm{Cl}$ (green) and $\mathrm{N}$ (blue) atoms. We obtained EXAFS fits for all three samples that are, graphically, in very good agreement with the experimental spectra (see Fig. 2), as also quantified by $R$-factor values lower than $2 \%$ for all the series of samples, see Table 3.

\subsection{Stability of UiO-67-Pt upon thermal reduction in $\mathbf{H}_{2}$ : ex situ XRPD and BET}

The stability of the UiO-67 framework upon thermal reduction in $\mathrm{H}_{2}$ has been checked by ex situ laboratory XRPD. The diffraction study reported in Fig. 3 guarantees that the crystallinity of the three samples is preserved in the reduction treatment (compare gray with black patterns). No reflection from the Pt phase could be detected from the gray patterns reported in Fig. 3, indicating that the possibly formed Pt-NPs should be relatively small.

Conversely, the thermal reduction in $\mathrm{H}_{2}$ affects, in a different way, both the available surface area and the available pore volume of the three samples. Table 4 displays the corresponding values, obtained from the analysis of the nitrogen adsorption/ desorption isotherms reported in Fig. 4. This observation agrees with the hypothesis of a partial occupation of available pore volume by Pt-NPs formed during thermal reduction in $\mathrm{H}_{2}$. The pore volume decrease is marginal for 10PMLS $(-4 \%)$, higher for 10PSF $(-9 \%)$ and very consistent for 5PMLS $(-29 \%)$, see Table 4. The origin of the different behaviour of the three samples will be understood by the advanced EXAFS/TEM analysis described in the following (see Section 3.4).

It is also worth noticing that the two samples with higher fraction of functionalized bpydc linker (10PMLS and 10PSF) exhibit a lower starting BET area and pore volume compared to 5PMLS, reflecting the partial occupancy of the pore volumes by the bulky $\mathrm{PtCl}_{2}$ (bpydc) linkers (note that the theoretical surface area of non-functionalized UiO-67 is $2850 \mathrm{~m}^{2} \mathrm{~g}^{-1}$ as calculated using the grand canonical Monte Carlo method with a probe of radius $=1.82 \AA){ }^{44}$

\subsection{Effect of the gas feed on UiO-67-bpydc-PtCl ${ }_{2}$ evidenced by quasi-simultaneous XANES and XRPD data collection}

The XANES spectra of the as-prepared 10PMLS (violet line) and of the thermally-treated MOF from RT to $623 \mathrm{~K}$ in $10 \% \mathrm{H}_{2} / \mathrm{He}$, $3 \% \mathrm{H}_{2} / \mathrm{He}$ and pure $\mathrm{He}$ are reported in Fig. $5 \mathrm{a}$ and compared to the XANES spectrum of a Pt-metal foil (grey line), employed as a reference for the presence of metallic Pt. When the sample is heated in $10 \% \mathrm{H}_{2} / \mathrm{He}$ (green) the XANES spectrum almost overlaps with that of Pt metal: indeed the absorption edge slightly shifts towards lower energies, the white line decreases and more defined post-edge features are formed. ${ }^{98}$ Conversely, the spectrum of the sample heated in pure He flow (red line) is fully comparable with that previously observed by us and assigned to isolated Pt sites still grafted to the bpydc linker after the loss of Cl ligands. ${ }^{98}$ In the latter spectrum, the post-edge features are smoother and the white line is slightly more intense with respect to the $10 \% \mathrm{H}_{2} / \mathrm{He} \mathrm{Pt}-\mathrm{UiO}-67$, but shifted at higher energy. The strong similarity between the XANES shape for the samples treated in $\mathrm{H}_{2}$ and that of the reference Pt metal foil unambiguously demonstrates that we produced $\mathrm{Pt}^{0}$ metal-like species. In addition, also the content of $\mathrm{H}_{2}$ in the gas feed clearly slightly affects the formation of $\mathrm{Pt}^{0}$ clusters as the activation in $3 \%$ of $\mathrm{H}_{2} / \mathrm{He}$ (orange) results in an intermediate situation.

The picture obtained from the XANES study is supported by the quasi-simultaneous XRPD data collection, Fig. 5b. The operando XRPD study, besides confirming the stability of the UiO-67 framework (already proven in the ex situ study reported in Fig. 3), allows the detection of the broad (111) and (200) reflections of the Pt metal phase at 13 and $15^{\circ}$ in $2 \theta$, respectively, for the sample reduced in $10 \% \mathrm{H}_{2}$. Such reflections are more visible in the inset (dashed blue lines).

The cell parameter and FWHM of the UiO-67 (333) reflection are summarized in Table 5 . The decrease of the cell parameter 

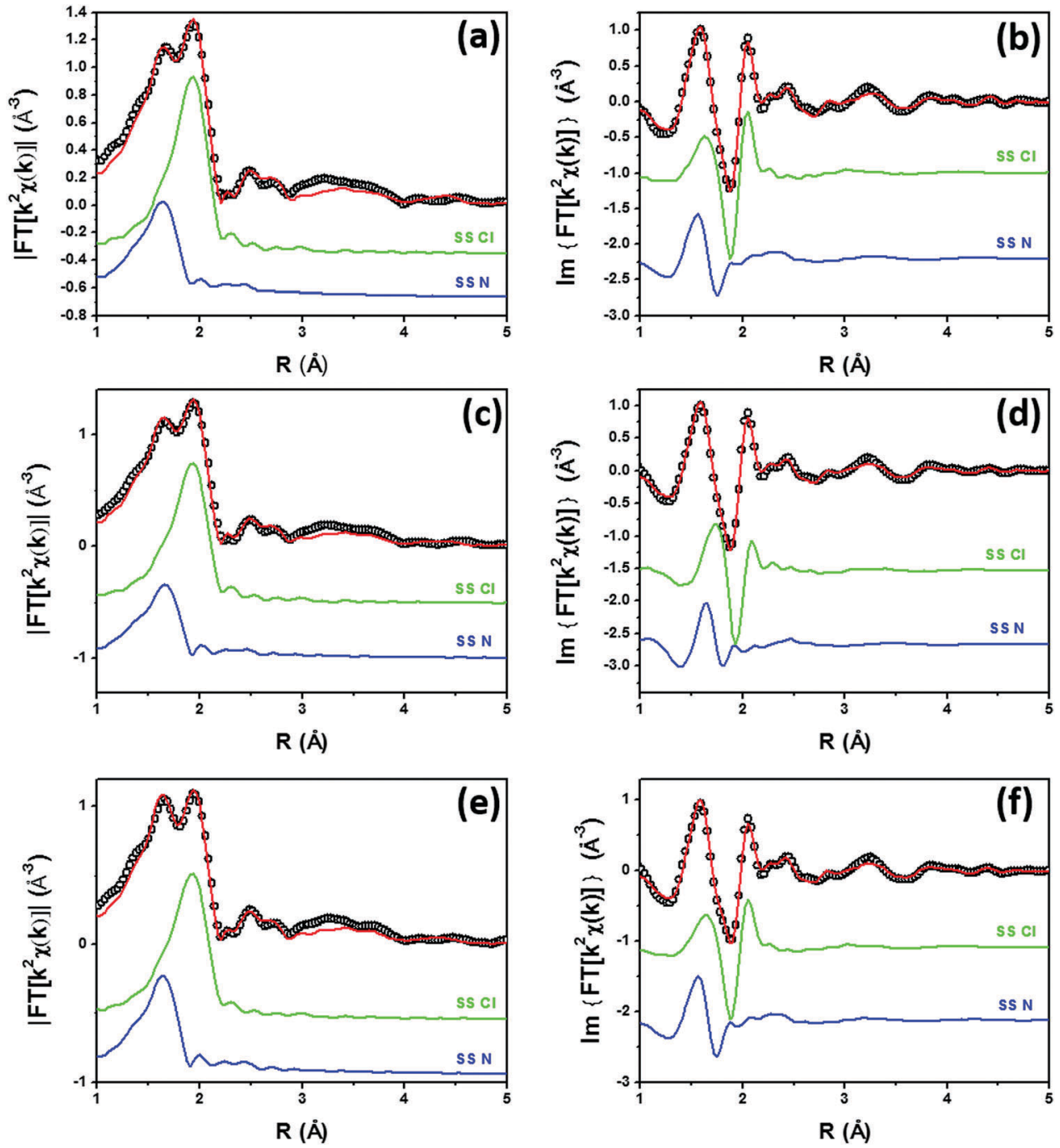

Fig. 2 Parts ( $a$ and b): $k^{2}$-weighted, phase uncorrected, modulus (a) and imaginary part (b) of the experimental and best fit FT EXAFS spectra for 5 PMLS in the as-prepared state (at RT, in air). The experimental data are shown as black open circles and the best fits with red solid lines. The SS contributions involving the $\mathrm{N}$ of bpydc (blue), and $\mathrm{Cl}$ (green) atomic neighbours are also reported, vertically translated for the sake of clarity. Parts (c and d) and (e and f) are the same as part ( $a$ and $b$ ) for 10PMLS and 1OPSF respectively. Interval: $\Delta k=3.1-17.0 \AA^{-1}$ and $\Delta R=1.0-4.8 \AA$, see Table 3 for the quantitative results of the fits.

during the activation is caused by the dehydration process. The increase of FWHM for the $10 \% \mathrm{H}_{2}$ activated sample may be due to the distortions in the UiO-67 structure induced by particle formation.

\subsection{Determination of the Pt local environments in UiO-67-Pt after $\mathrm{H}_{2}$-TPR by static EXAFS}

The samples were heated up to $623 \mathrm{~K}$ in $10 \% \mathrm{H}_{2} / \mathrm{He}$, while collecting operando XAS (XANES and EXAFS) spectra to monitor the evolution of electronic and structural properties of Pt-sites during TPR. Operando XANES spectra are reported in Fig. 6a for the 10PMLS sample. The XANES spectrum for the as-prepared material (red spectrum in Fig. 6a) is characterized by the absence of any defined pre-edge/edge peaks, and by a rather intense white line feature at $\sim 11560 \mathrm{eV}$. While increasing the temperature during TPR, clear modifications occur in the
XANES spectra, including a progressive reduction of the white line intensity and the evolution of more structured post-edge features at $\sim 11575 \mathrm{eV}$ and at $\sim 11590 \mathrm{eV}$, well evident in the final spectrum at $623 \mathrm{~K}$ (black spectrum in Fig. 6a). As anticipated in Section 3.3, this shape of the XANES spectrum matches the spectrum of the Pt-metal foil. This evidence is further supported by the evolution of the $k^{2}$-weighted, phase uncorrected FT of the corresponding EXAFS curves (Fig. 6b). The same behaviour has been observed in the XANES and EXAFS spectra of 5PMLS and 10PSF samples, as shown in Fig. S3 in the ESI. $\dagger$

When the XANES spectra collected at $623 \mathrm{~K}$ demonstrated no further time-dependent changes, we cooled down the sample to RT for high-quality EXAFS data collection. Fig. 7 compares the modulus and the imaginary part of the FT of the EXAFS spectra for 10PMLS in the initial state (as-prepared material, at RT 

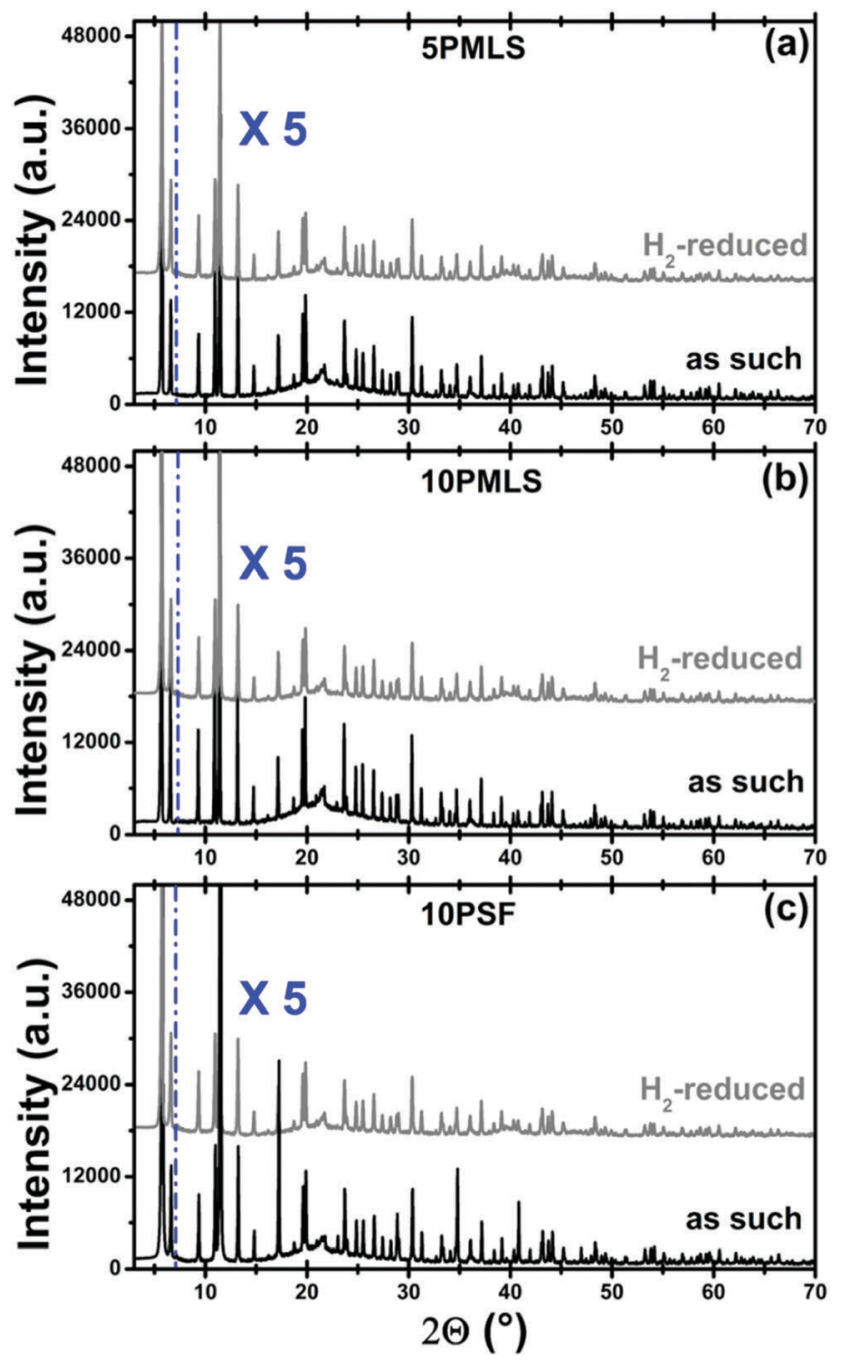

Fig. 3 Part (a): the XRPD pattern of sample 5PMLS at RT for the as-prepared sample (black) and after $\mathrm{H}_{2}$-TPR (grey). The broad reflection around $2 \theta=22^{\circ}$ is due to the window of the cell. Cu K $\mathrm{K}_{\alpha} \lambda=1.541 \AA$. Patterns were vertically shifted for clarity and the $7-70^{\circ}$ region has been multiplied by a factor of 5 to better appreciate the reflections in the high $2 \theta$ region. Parts ( $b$ and $c$ ): the same as part (a) for the 10PMLS and 10PSF samples, respectively.
Table 4 Surface area and pore volume of fresh and spent 5PMLS, 10PMLS and 10PSF samples. The theoretical surface area of non-functionalized UiO-67 is $2850 \mathrm{~m}^{2} \mathrm{~g}^{-1}$ as calculated using the grand canonical Monte Carlo method with a probe of radius $=1.82 \AA^{44}$

\begin{tabular}{lllll}
\hline & & & $\begin{array}{l}\text { Total pore } \\
\text { volume } \\
\left(\mathrm{cm}^{3} \mathrm{~g}^{-1}\right)\end{array}$ & $\begin{array}{l}\text { Total pore } \\
\text { volume } \\
\text { decrease }(\%)\end{array}$ \\
\hline 5PMLS & 2562 & -31 & 1.04 & -29 \\
5PMLS spent & 1766 & & 0.74 & \\
& & & & \\
10PMLS & 2361 & -9 & 0.97 & -4 \\
10PML Spent & 2147 & & 0.93 & \\
& & & & -9 \\
10PSF & 2234 & -8 & 0.88 & \\
10PSF spent & 2055 & & &
\end{tabular}

before TPR, red curves) and in the final state, after TPR and subsequent cooling at RT (orange curves). For comparison, Fig. 7 also reports the corresponding spectra of Pt-metal foil (grey curves). The same EXAFS spectra of 5PMLS and 10PSF samples are shown in Fig. S4, ESI. $\dagger$ After activation, the modulus is characterized by four significant contributions centred around $1.7 \AA, 1.9 \AA, 2.2 \AA$ and $2.6 \AA$ (Fig. 7a). The first two peaks, as already discussed in Section 3.1, are associated with the Pt-N and $\mathrm{Pt}-\mathrm{Cl}$ SS paths, respectively, and are in phase with signals present in the red spectrum. The two maxima at $2.2 \AA$ and $2.6 \AA$ correspond both to the SS of a single Pt-Pt contribution of $\mathrm{Pt}$ metal (a double-shaped modulus of the FT is typical of a single distance in EXAFS when the scattering atom is a high $\mathrm{Z}$ one such as e.g. $\mathrm{Ag}^{155} \mathrm{In}^{156}$ or $\mathrm{Pt}^{92}$ ).

During the thermal treatment, the signals from Pt-N and $\mathrm{Pt}-\mathrm{Cl}$ coordination shells decrease while the peaks at $2.2 \AA$ and $2.6 \AA$ rise, see Fig. $6 \mathrm{~b}$. This is evidence of the nucleation of the $\mathrm{Pt}^{0}$ metal NPs, formed after the progressive detachment of the Pt framework atoms. It is worth noting that even if the intensity of the $\mathrm{Pt}-\mathrm{Cl}$ contribution is drastically diminished with respect to the as-prepared material, there is still a significant residual signal of $\mathrm{Pt}-\mathrm{Cl}$ in the spectrum collected at the end of the treatment.

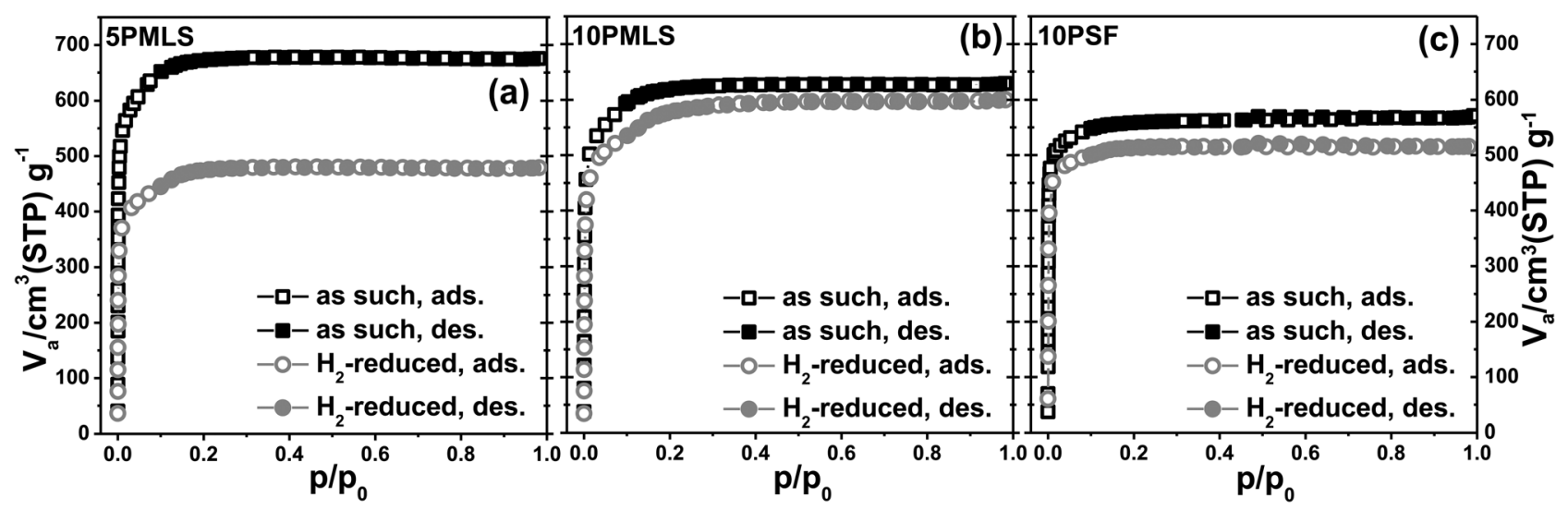

Fig. 4 Part (a): nitrogen adsorption/desorption isotherms for the 5PMLS sample as such (black squares) and after the $\mathrm{H}_{2}$-TPR (grey circles). Open and full symbols refer to adsorption and desorption runs, respectively. Parts ( $b$ and $c$ ): the same as part (a) for the 10PMLS and 10PSF samples, respectively. 

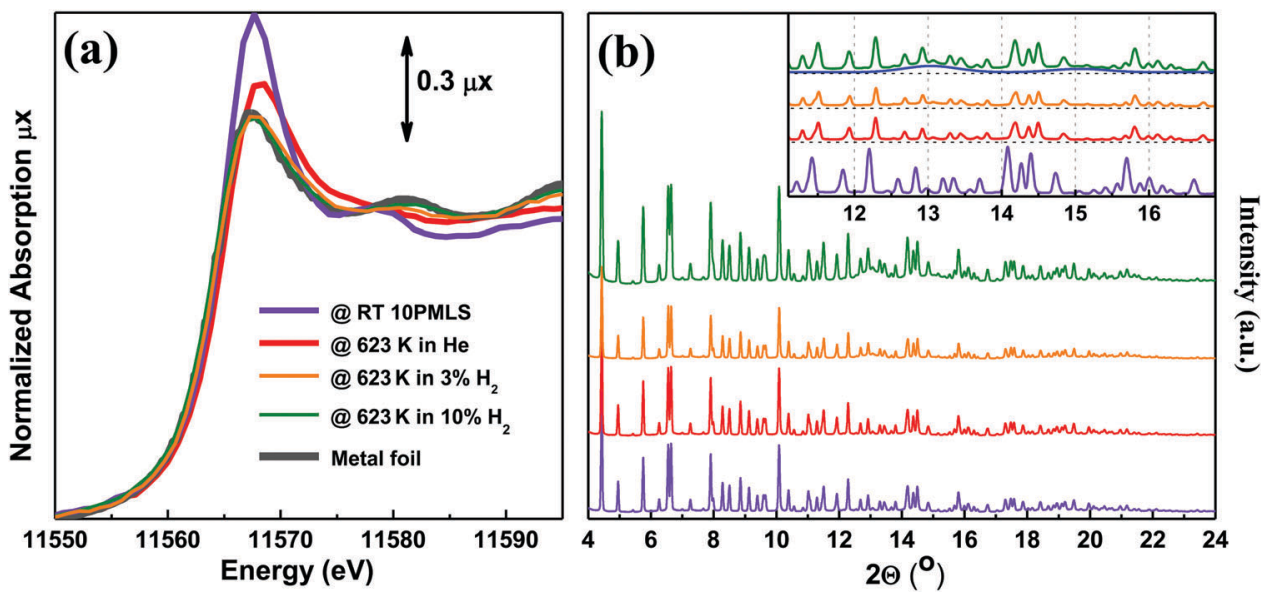

Fig. 5 Part (a): operando Pt $\mathrm{L}_{\| I}$ edge XANES spectra of as-prepared 10PMLS at RT (violet) and after thermal treatment: in $3 \%$ and $10 \% \mathrm{H}_{2} / \mathrm{He}_{\mathrm{N}}$ (orange and green, respectively), and in pure He flux (red). The XANES spectrum of Pt metal foil (grey) is reported as a reference. Part (b): operando XRPD patterns taken simultaneously with the XANES spectra reported in part (a). $\lambda=0.51353(1) \AA$. The inset shows the region containing Pt(111) and (200) reflections at 13 and $15^{\circ}$ in $2 \theta$, respectively. The blue curve represents the simulated scattering signal for the $2.3 \mathrm{~nm}$ Pt nanoparticle with cell parameter $d=3.92 \AA$. The same experiments repeated for 5PMLS and 10PSF samples resulted in an equivalent behavior. The summary of the Rietveld refinements of these XRPD patterns is reported in Table 5 .

Table 5 Summary of the Rietveld refinements of the XRPD patterns reported in Fig. 5b

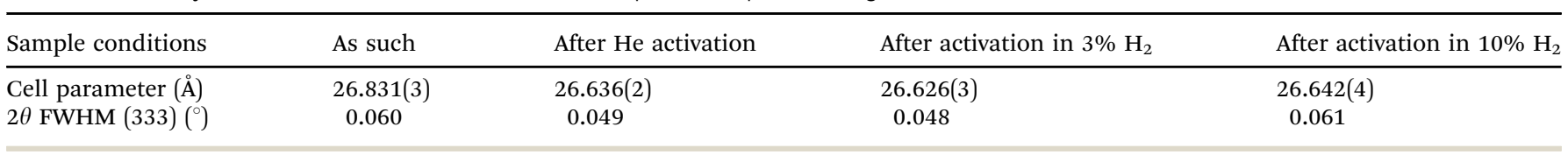
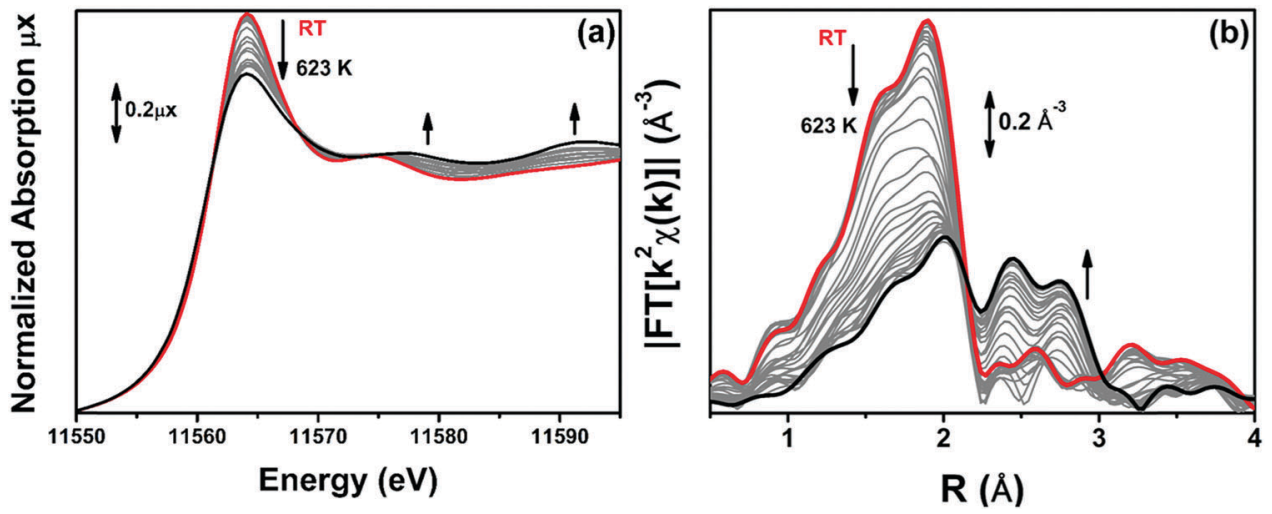

Fig. 6 Part (a): sequence of Pt $\mathrm{L}_{\text {III }}$ edge operando XANES spectra of 10PMLS during TPR, collected at the starting point at RT (red) and upon heating to $623 \mathrm{~K}$ in $10 \% \mathrm{H}_{2} / \mathrm{He}$ (grey) until the steady state at $623 \mathrm{~K}$ is reached (black). Part (b): the same as part (a) for the $k^{2}$-weighted, phase uncorrected FT of the corresponding EXAFS curves.

The formation of Pt-NPs is further supported by TEM analysis on the three UiO-67-Pt samples. TEM shows that NPs are produced after the TPR for the all sample series. Fig. 8 presents the distribution of particle size (parts (a), (d) and (g)) weighted by the number (blue bars) and by the volume (green bars) of the particles $^{92,157}$ and the TEM microscopy images at low (parts (b), (e) and (h)) and at high (parts (c), (f) and (i)) magnification. In all the samples, Pt-NPs are well dispersed in the MOF matrix and no evidence of NP aggregation has been observed.

The particle size distribution (blue histograms in Fig. 8a, $\mathrm{d}$ and $\mathrm{g}), w_{\mathrm{P}}\left(d_{i}\right)$, provides the fraction $w_{\mathrm{P}}$ of NPs having a diameter $d$ in the interval $\left[d_{i}-\varepsilon<d \leq d_{i}+\varepsilon\right]$, being $\varepsilon=0.25 \mathrm{~nm}$ in the adopted cases. From our study, it emerges that $w_{\mathrm{P}}\left(d_{i}\right)$ depends on the Pt loading and on the synthesis method. Between samples prepared with the PMLS approach, an average smaller size is obtained with the sample with lower Pt loading: $\langle d\rangle=(2.6 \pm 0.8) \mathrm{nm} v s .(3.5 \pm 1.2) \mathrm{nm}$, for 5PMLS and 10PMLS, respectively. Comparison of the samples with the same loading demonstrates that the PMLS method is more efficient in keeping a low particle size than the PSF, being $\langle d\rangle=(4.4 \pm 2.4) \mathrm{nm}$ for 10PSF. All reported $\langle d\rangle$ values refer to the particle distribution weighted by number of particles (blue distributions in Fig. 8a, d and g, usually reported in the TEM studies). When the same distributions are weighted by the volume, 10PSF clearly exhibits a bimodal 

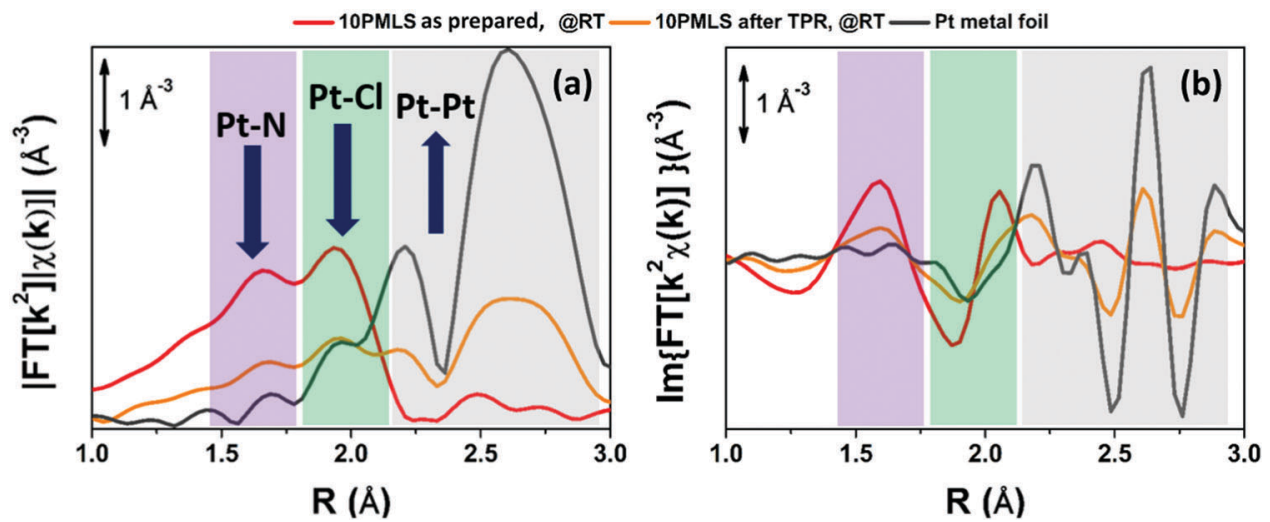

Fig. $7 k^{2}$-weighted, phase uncorrected, modulus (a) and imaginary part (b) of the experimental FT EXAFS spectra for 10PMLS in the as-prepared state at RT in air (red) and after TPR up to $623 \mathrm{~K} \mathrm{in} 10 \% \mathrm{H}_{2} / \mathrm{He}$ and subsequent cooling to RT (orange). The corresponding spectra of the Pt-metal foil are also reported (grey) for comparison.

(a)
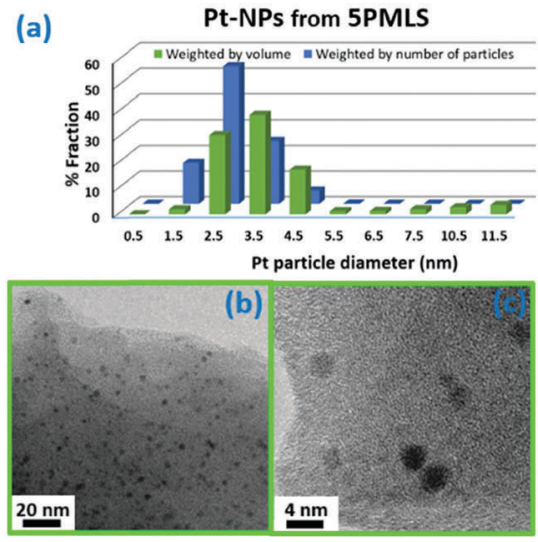

(d)

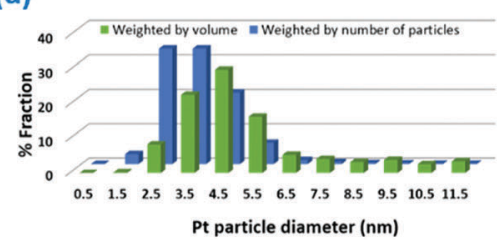

(e)

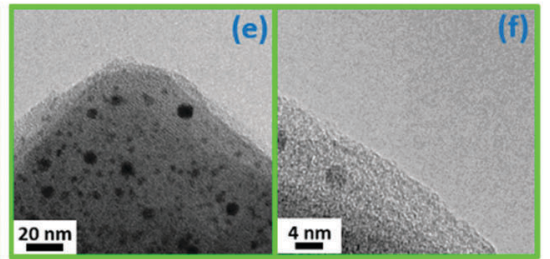

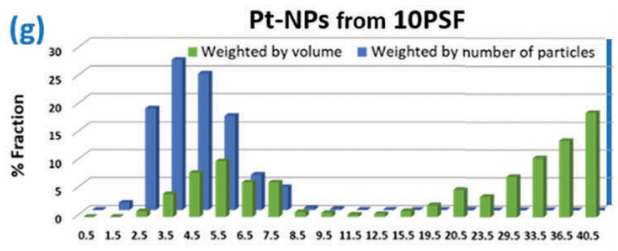

Pt particle diameter $(\mathrm{nm})$

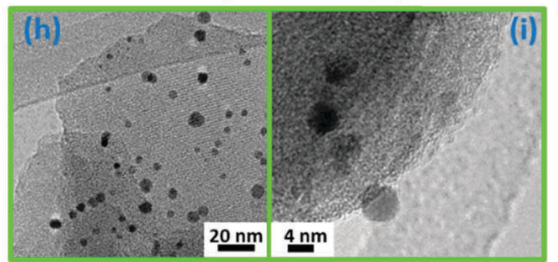

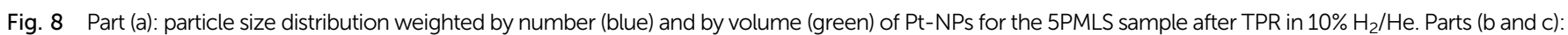

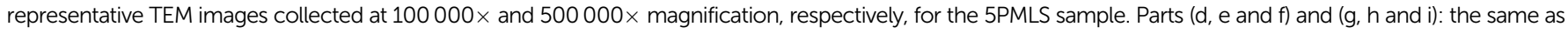
parts ( $a, b$ and c) for 10PMLS and 10PSF, respectively. The total number of counted particles is: 1545 for 5 PMLS, 2135 for $10 P M L S$ and 1259 for $10 P S F$.

distribution. As all Pt atoms contribute to the EXAFS signal, a large particle has a greater weight in the overall EXAFS signal than a small one. For this reason, when EXAFS and TEM studies are compared, the relevant size distribution is the volume-weighted one $\left(w_{\mathrm{v}}\left(d_{i}\right)\right.$, green histograms in Fig. $8 \mathrm{a}, \mathrm{d}$ and $\left.\mathrm{g}\right),{ }^{92,157}$ that is obtained from the particle weighted one according to eqn (2):

$$
w_{\mathrm{V}}\left(d_{i}\right)=\frac{4 \pi}{3 V}\left(\frac{1}{2} d_{i}\right)^{3} w_{\mathrm{P}}\left(d_{i}\right),
$$

where: $V=\sum_{i=1}^{n} \frac{4 \pi}{3}\left(\frac{1}{2} d_{i}\right)^{3} w_{\mathrm{P}}\left(d_{i}\right)$.

Once the shape of a NP is known (e.g. from the TEM study) the average coordination number of a given fcc NP is unambiguously given by its diameter, $N\left(d_{i}\right) .{ }^{158,159}$ Successively, using the $w_{\mathrm{v}}\left(d_{i}\right)$ distribution it is possible to estimate the average coordination number of the whole particle distribution $\left(N_{\mathrm{Pt}}\right)$ as:

$$
N_{\mathrm{Pt}}=\sum_{i=1}^{n} N\left(d_{i}\right) w_{\mathrm{V}}\left(d_{i}\right)
$$

The values of $N_{\mathrm{Pt}}$ for the three samples are given in Table 6 .
Quantitative analysis of the EXAFS spectra collected at RT after the thermal treatment was performed assuming the presence of the [bpydc- $\mathrm{PtCl}_{2}$ ] linker component, already used to fit the spectra of the as-prepared materials, and the $\mathrm{Pt}^{0}$ metal cluster component, with fixed $N_{\mathrm{Pt}}$.

The assumption of the coexistence of two structural components increases significantly the number of variables that must be taken into account in the EXAFS analysis. The contribution of the two phases in the EXAFS fit has been distinguished by multiplying the amplitude of the EXAFS equation for the metal $\mathrm{Pt}^{0}$ phase by a free variable $x$, representing the content of Pt-NPs, and the linker phase by a factor of $(1-x)$. In this manner, the concentration of Pt-NPs formed can be figured out. The fit has been performed in the $\Delta R$ range of (1.0-3.1) $\AA$, defined considering the first coordination shell of the Pt-metal phase.

To achieve a reliable EXAFS fit on such a complex system, we set a series of selected parameters based on the analysis of two pure phases: as-prepared materials (Table 3 and Fig. 2) and reference Pt-metal foil (Table S1 and Fig. S5, ESI $\dagger$ ). All parameters of the isolated framework Pt phase have been fixed to 
Table 6 Best-fit values of the parameters optimized in the EXAFS fits for the three samples (5PMLS, 10PMLS and $10 P S F)$ after TPR in $10 \% \mathrm{H}_{2} / \mathrm{He}$-flow at $623 \mathrm{~K}$ (data collected at RT). The fits were performed in the $k$-space interval $\Delta k=(3.1-17.0) \AA^{-1}$ and $R$-space interval $\Delta R=(1.0-3.1) \AA$. The bold parameters were fixed in the fit and have no associated error

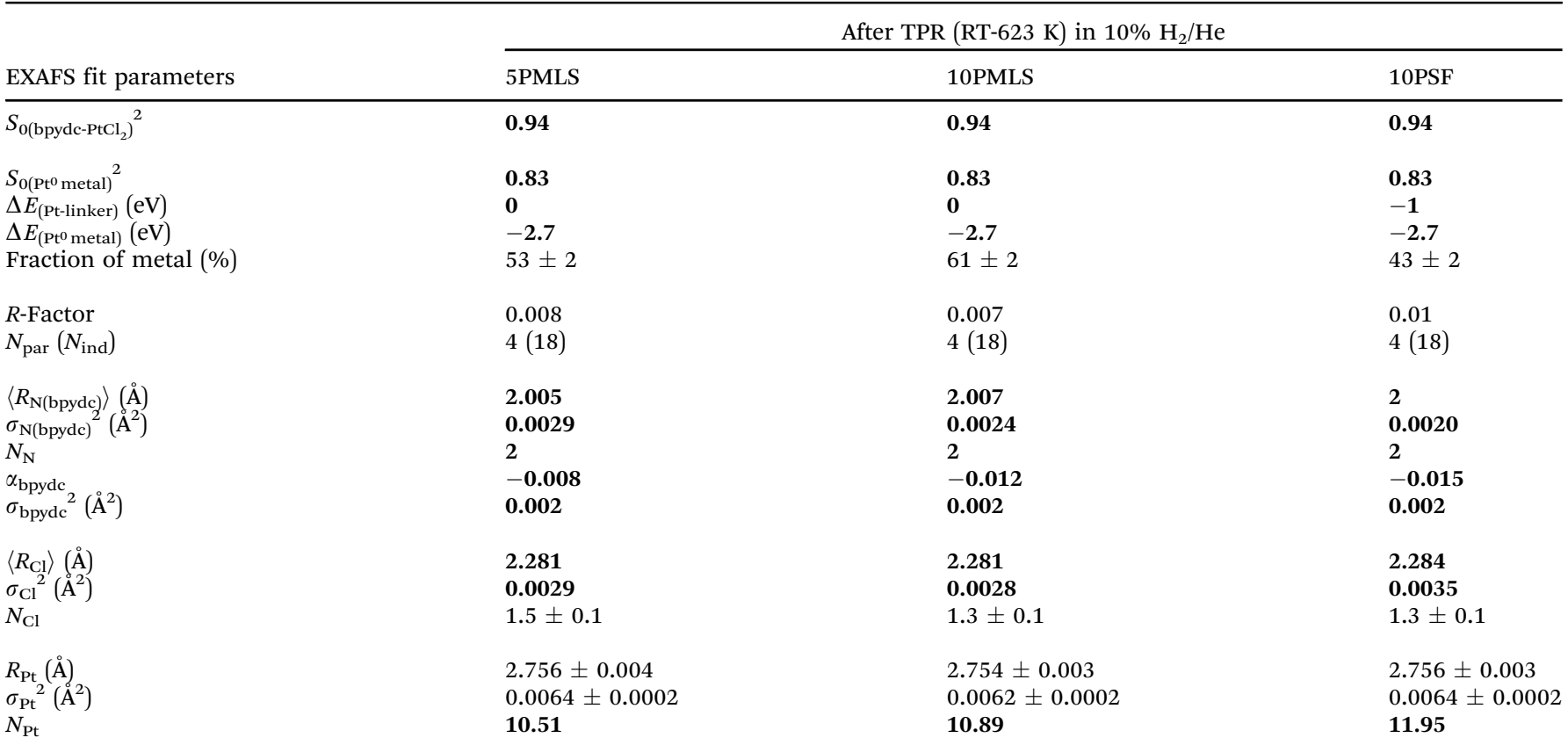

the values optimized in Table 3, with the only exception of the $N_{\mathrm{Cl}}$ coordination number. Indeed, along the TPR treatment, a fraction of the Pt atoms that remained anchored to the MOF framework may have lost one or two Cl ligands. It should be noted that the Pt-NP formation is not immediate, but it should evolve through several intermediate steps such as [bpydc-Pt(II)Cl $]^{-}$, $[\text { bpydc-Pt(II) }]^{2-},\left[\right.$ bpydc-Pt $\left.{ }^{0}\right]$ etc., along the reaction paths to Pt-NPs. Indeed, considering the spectrochemical series, it is energetically favourable to break firstly the $\mathrm{Pt}-\mathrm{Cl}$ bond with respect to the $\mathrm{Pt}-\mathrm{N}$ one to bpydc; ${ }^{160}$ this behaviour is also supported by our previous EXAFS results. ${ }^{98}$

Concerning the Pt-NP phase, the only optimized parameters were $\sigma_{\mathrm{Pt}}{ }^{2}$ and $\mathrm{R}_{\mathrm{Pt}-\mathrm{Pt}}$, which can differ significantly comparing bulk $\mathrm{Pt}^{0}$ and Pt-NPs. As for the first shell Pt-Pt coordination number, $N_{\mathrm{Pt}}$, it was fixed based on TEM results that allows us to obtain the average $N_{\mathrm{Pt}}$ based on the volume-weighted particle size distribution reported in Fig. 8a, d and g, ${ }^{92,157-159,161,162}$ assuming a spherical shape for the Pt-NPs, see eqn (3).

The results of the EXAFS analysis of the three samples after the TPR are reported in Table 6, while the quality of the fit can be appreciated in Fig. 9. The agreement between experimental (open black circles) and theoretical (red lines) curves is remarkable for such a complex system, taking into account that the model uses only 4 free parameters $\left(x, N_{\mathrm{Cl}}, \sigma_{\mathrm{Pt}}{ }^{2}\right.$ and $\left.R_{\mathrm{Pt}-\mathrm{Pt}}\right)$. Such a result can be obtained only if the constraints used for all the non-optimized parameters have been properly set.

EXAFS analysis revealed that, at the end of the TPR run, the Pt-MOFs synthesized by the PMLS method produce more Pt-NPs than the PSF. Indeed, 5PMLS and 10PMLS yielded 53\% and $61 \%$ of Pt-NPs compared to the $43 \%$ obtained for $10 \mathrm{PSF}$. The $\sigma_{\mathrm{Pt}}{ }^{2}$ for the formed Pt-NPs, $(0.0064 \pm 0.0002) \AA^{2}$, is higher than the value derived from the analysis of bulk Pt metal, $\sigma_{\mathrm{Pt}(\text { foil })}{ }^{2}=(0.0047 \pm 0.0001) \AA^{2}$, as expected due to the higher structural disorder in the Pt-NP phase formed during TPR. Also the $\mathrm{Pt}-\mathrm{Pt}$ distance undergoes a small contraction with respect to the bulk value of about $0.01 \AA$, in agreement with what is reported in the literature. ${ }^{163-165}$

\subsection{Determination of the evolution of the Pt local environment in UiO-67-Pt along TPR by operando EXAFS}

The EXAFS analysis of the spectra collected under operando conditions along the TPR experiment has followed the advanced fourstep procedure described in detail in Section 2.5. The results are summarized in Fig. 10 for the three samples. We selected the firstshell Pt-Pt SS path as an indicator for Pt-NP formation, whereas the $\mathrm{Pt}-\mathrm{N}$ (bpydc) and Pt-Cl SS paths are representative of the Pt-linker component. Fig. 10 shows the time-dependent behaviour of the $N_{i} \cdot x_{i} \cdot S_{0 i}^{2}$ product between the coordination number $N_{i}$, the relative fraction $x_{i}$ and the scattering amplitude factor $S_{0 i}{ }^{2}$, with $i$ indicating the three Pt atomic neighbours considered, i.e. $\mathrm{N}, \mathrm{Cl}$ and Pt. In the TPR-EXAFS analysis it is not possible to quantify the absolute content of Pt-NPs, because both particle size (and thus the average $\left.N_{\mathrm{Pt}}\right)$ and particle fraction $(x)$ increase along the experiment and a TEM study, as we had for the final sample, for the intermediate steps during TPR would be extremely challenging and beyond the scope of the present work. Notwithstanding this limitation, it is meaningful to observe the comparison of the relative weight of the $\mathrm{Pt}-\mathrm{Pt}$ contribution with respect to the $\mathrm{Pt}-\mathrm{Cl}$ and $\mathrm{Pt}-\mathrm{N}$ ones during the TPR. Moreover, the Pt-Cl and $\mathrm{Pt}-\mathrm{N}$ contributions decrease significantly at $623 \mathrm{~K}$, and with the same trend.

Data analysis reveals that the sample synthesized with the PSF method, which starts from an initial situation with less $\mathrm{Cl}$, 

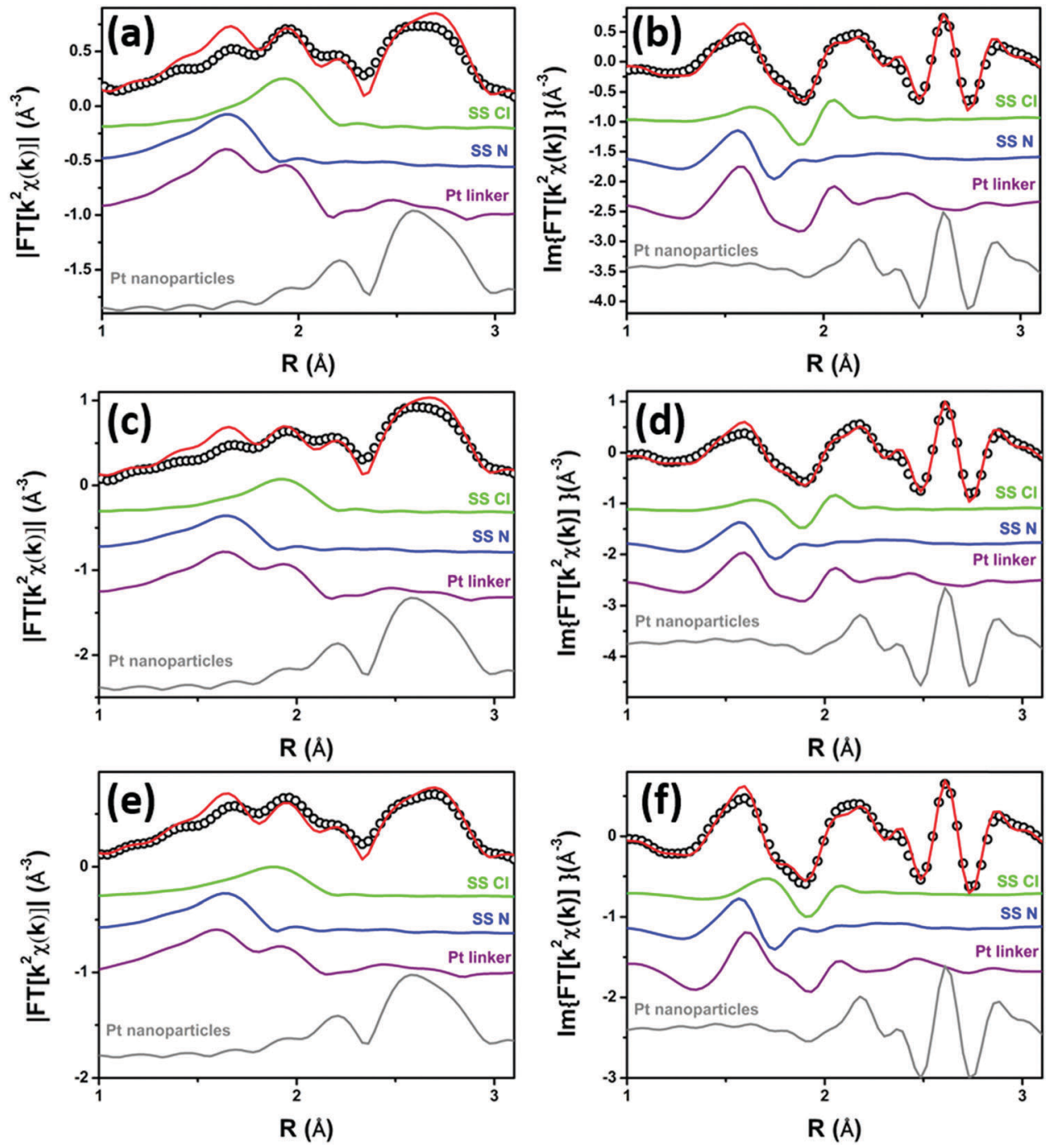

Fig. 9 Parts ( $a$ and $b$ ): $k^{2}$-weighted, phase uncorrected, modulus (a) and imaginary part (b) of the experimental and best fit FT EXAFS spectra for 5 PMLS under static conditions at $623 \mathrm{~K}$ in $10 \% \mathrm{H}_{2} / \mathrm{He}$. The experimental data are shown as black dots and the best fit with a red solid line. Moreover, the SS contributions involving the $\mathrm{N}$ of bpydc (blue), and $\mathrm{Cl}$ (green) atomic neighbours as well as the sum of SS and MS involving the Pt linker (violet) and the Pt-NP (grey) contributions are reported. Parts ( $c$ and $d$ ) and (e and f): the same as parts ( $a$ and b) for the 10PMLS and 10PSF respectively.

is less prone to form Pt-NPs than the samples synthesized with the PMLS method.

\subsection{Determination of the Pt-NP concentrations with XANES linear combination analysis supported by PCA analysis}

The operando XANES spectra collected during $\mathrm{H}_{2}$-TPR have been analysed using principal component analysis (PCA) with Fitit software ${ }^{166}$ and linear combination analysis (LCA) with Athena software. ${ }^{132}$ In the absence of experimental error, PCA will give the exact number of meaningful abstract components, i.e. the exact dimension of the experimental dataset. Unfortunately, perfect data are not attainable and noise unavoidably produces a number of extra-components whose retention leads, clearly, to the complete reproduction of the entire dataset, including experimental errors. ${ }^{167}$ For this reason a series of statistical estimators are used in order to deduce the correct number of principal components (PCs). ${ }^{167-169}$ One of them is the so called Malinowski indicator factor (IND). It consists of an empirical function that reaches a minimum in the presence of the correct number of components making it possible to drastically reduce the experimental error, which contributes to the data reproduction. Based on the imbedded error (IE) and the $\mathrm{IND}^{170}$ (Fig. S6, ESI $\dagger$ ), PCA has revealed five components for all the UiO-67-Pt samples. However, recent reports showed that this method can sometimes fail. ${ }^{171-173}$ In particular IND performance critically depends on the amount of noise in the data and may result in considerable overestimation of the number of components; moreover the accuracy of the component recovery seems to depend on the size of the dataset. ${ }^{173}$ For these reasons in our LC reconstruction, we considered only the first two main components which are predominant over less important data features (i.e. intermediates of reactions) and noise, as described in Fig. S7 of the ESI. $\dagger$ Being primarily interested in tracking the Pt-NP formation during the TPR, we adopted a quick and 

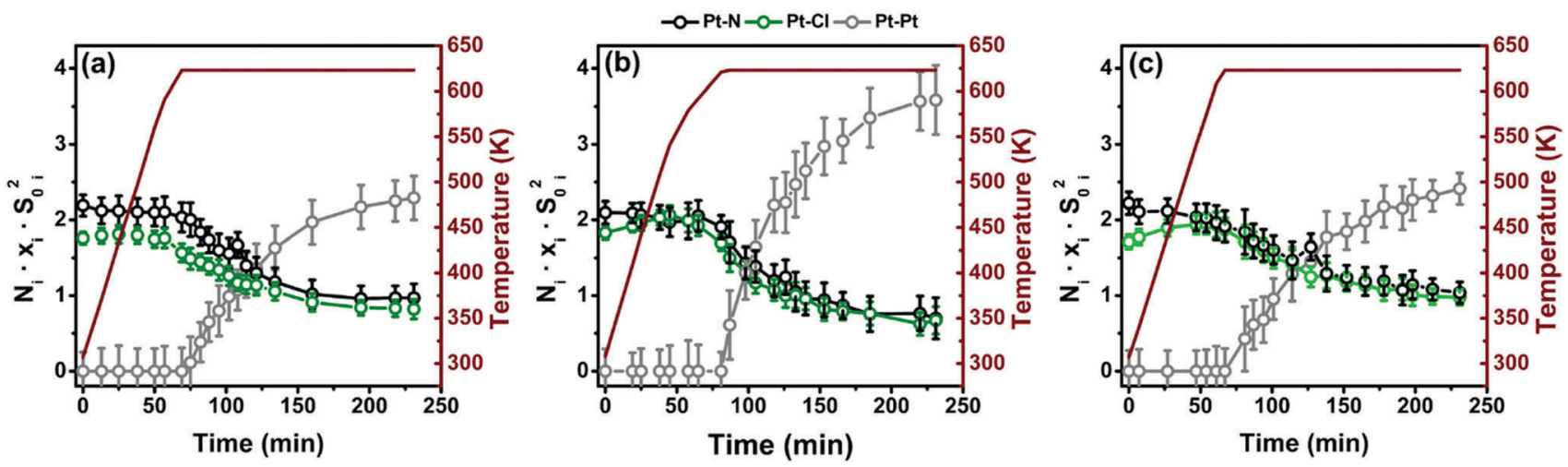

Fig. 10 (a) Results of the simultaneous parametric analysis of operando EXAFS collected during TPR for 5PMLS. The amplitude factor reported in the figure as a function of time is defined by the product between the coordination number $N_{i}$, the relative fraction $x_{i}$ and by the scattering amplitude factor $\mathrm{S}_{0}{ }^{2}$, where $i$ denotes the three kinds of SS considered, i.e. Pt-N and Pt-Cl for the Pt-linker component, and Pt-Pt for the Pt-NP phase (N in black, $\mathrm{Cl}$ in green and Pt in grey). Parts ( $b$ and $c$ ) are the same as part (a) for 10PMLS and 10PSF, respectively.

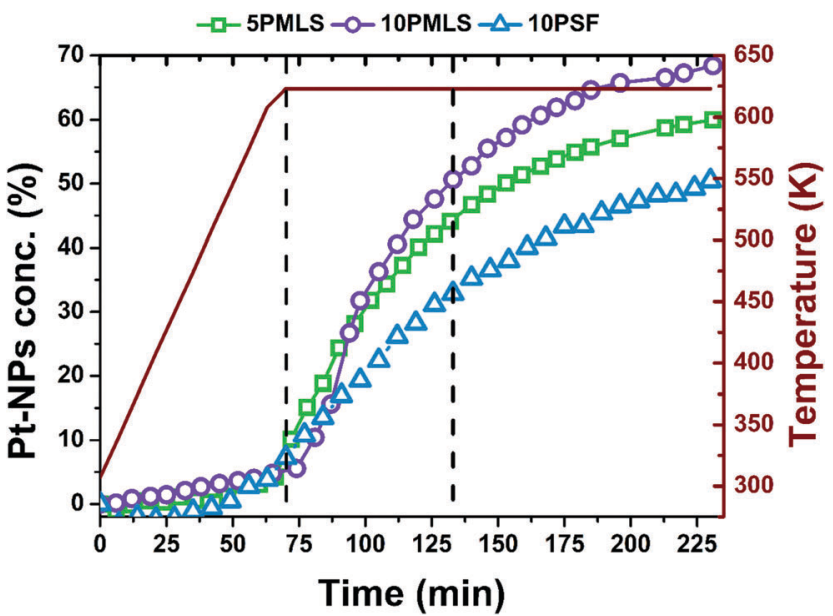

Fig. 11 Evolution of Pt-NP percentage concentration depending on time and on temperature (burgundy colour, reported also on $y$-axis) for the 5PMLS (green), 10PMLS (violet) and 10PSF (cyan). The first black vertical line represents the reaching of $623 \mathrm{~K}$ and the second vertical line is after $1 \mathrm{~h}$ at constant temperature.

informative method, namely LCA, widely used to analyse a series of time evolving XANES spectra. ${ }^{124,174-176}$ We have selected as references for operando XANES LCA only the two key-species present in the whole sample series, i.e. $\mathrm{Pt}^{0}$ metal sites (Pt-metal foil XANES spectrum) and $\left(\mathrm{PtCl}_{2}\right)$ bpydc complexes (RT spectra collected before the TPR). The $R$-factors obtained for LCA are on the order of
$10^{-5}$ for each spectrum, meaning that the employed references are able to provide an adequate reproduction of the experimental spectra, although possible Cl-deficient Pt-linker species are not included in LCA. Fig. 11 reports the result of the linear combination analysis showing the behaviour of the Pt-NP component as a function of time and temperature for the 5PMLS (green), 10PMLS (violet) and 10PSF (cyan). Noteworthily, the Pt-NP concentration increases slightly for all the samples until the temperature of $623 \mathrm{~K}$ is reached. At $623 \mathrm{~K}$ there is a sudden increase in the growth rate of Pt-NPs, which reaches a plateau after almost $4 \mathrm{~h}$ at constant temperature. The same exponential behaviour has been observed for the different samples, although the concentration of the formed NPs varies for the three investigated samples. Indeed, the MOF synthesized by the PMLS method, as already seen in EXAFS analysis, yields more Pt-NPs than the PSF method. In Table 7 are reported the Pt-NP concentration values when the temperature of $623 \mathrm{~K}$ is just reached, after $1 \mathrm{~h}$ and $c a .4 \mathrm{~h}$ at constant temperature and, finally, at RT after TPR. The values derived with EXAFS and XANES LCA after TPR are equivalent within their respective errors (compare the last two columns in Table 7).

\section{Conclusions}

In this work, we demonstrate the successful Pt-functionalization of UiO-67 MOFs with two different synthesis methods (PMLS and PSF) and Pt loadings (2.8 and 5.5 wt\%). In addition, we show, by means of XANES, that Pt-functionalized MOFs are sensitive to the

Table 7 Values of Pt-NP concentration (\%) as derived from XANES linear combination analysis (LCA) and TPR-EXAFS at different time/temperature points for 5PMLS, 10PMLS and 10PSF

\begin{tabular}{|c|c|c|c|c|c|}
\hline \multirow[b]{2}{*}{ Sample } & \multicolumn{4}{|c|}{ From XANES LCA analysis } & \multirow{2}{*}{$\begin{array}{l}\text { From EXAFS, } \\
\text { see Table } 6 \\
\text { Pt-NPs }(\%) \text { at RT }\end{array}$} \\
\hline & $\begin{array}{l}\text { Pt-NPs }(\%) \text { at } \\
623 \mathrm{~K}(0 \mathrm{~h})\end{array}$ & $\begin{array}{l}\text { Pt-NPs }(\%) \text { at } \\
623 \mathrm{~K}(\text { after } 1 \mathrm{~h})\end{array}$ & $\begin{array}{l}\text { Pt-NPs }(\%) \text { at } \\
623 \mathrm{~K} \text { (after } 4 \mathrm{~h})\end{array}$ & $\begin{array}{l}\text { Pt-NPs(\%) after } \\
\text { cooling at RT }\end{array}$ & \\
\hline 5PMLS & $4 \pm 1$ & $44 \pm 2$ & $59 \pm 2$ & $57 \pm 3$ & $53 \pm 2$ \\
\hline 10PMLS & $10 \pm 1$ & $57 \pm 2$ & $68 \pm 2$ & $61 \pm 1$ & $61 \pm 2$ \\
\hline 10PSF & $11 \pm 1$ & $35 \pm 2$ & $49 \pm 2$ & $48 \pm 2$ & $43 \pm 2$ \\
\hline
\end{tabular}


gas feed during temperature activation (from RT to $623 \mathrm{~K}$ ): (i) in pure $\mathrm{He}$ the $\mathrm{Cl}$ ligands are lost but the $\mathrm{Pt}$ site remains grafted to the linker, while (ii) in $\mathrm{H}_{2}$ Pt-NPs are formed. The formation of Pt-NPs has been followed during TPR with operando EXAFS in $\mathrm{H}_{2}$ /He flow, successively analyzed with a parametric approach based on the Einstein model to minimize the correlation among optimized parameters. A simultaneous loss of $\mathrm{Cl}$ and $\mathrm{N}$ ligands has been observed under isothermal conditions once $623 \mathrm{~K}$ was reached. The TEM analysis of the recovered sample revealed that NPs were produced during the TPR treatment for the whole set of samples. We found that the size distribution of the NPs depends on the Pt loading and on the synthesis method. Samples prepared with the PMLS approach present an average smaller diameter for the sample with lower Pt loading: $\langle d\rangle=(2.6 \pm 0.8) \mathrm{nm} v s$. $(3.5 \pm 1.2) \mathrm{nm}$, for 5PMLS and 10PMLS, respectively. In addition, the comparison between the samples with the same Pt loading demonstrate that the PMLS method is more apt to keep a low particle size than the PSF method, with $\langle d\rangle=(4.4 \pm 2.4) \mathrm{nm}$ for 10PSF. The particle size distribution obtained from the TEM study allowed us to fix the Pt-Pt coordination number and to perform an advanced EXAFS data analysis on the samples at the end of the TPR experiment allowing the quantitative determination of the fraction of Pt atoms in the NP phase to be 53, 61 and $43 \%$ for 5PMLS, 10PMLS and 10PSF respectively. These values have been quantitatively confirmed by linear combination analysis of the XANES spectra. Operando XANES experiments were supported by quasi simultaneous XRPD data collection testifying the resistance of the UiO-67 framework to TPR. In situ XANES/EXAFS studies were supported by ex situ XRPD and BET analyses, confirming the framework stability and testifying a loss of the internal volume after TPR due to the formation of Pt-NPs insides the MOF pores, more relevant in the sample where smaller Pt-NPs were formed.

\section{Conflicts of interest}

There are no conflicts to declare.

\section{Acknowledgements}

We are indebted to S. Bordiga (University of Turin) for having taken part in the experiments in Lund and for fruitful discussion. LB, KAL, ALB, AAG, AVS and CL acknowledge the Megagrant of the Russian Federation Government to support scientific research at the Southern Federal University, no. 14.Y26.31.0001. The authors are grateful to MAX-lab for the allocation of the beam time (proposal 20140449) and to Dr Stefan Carlson for the technical support during the experiments at the I811 beamline. We also acknowledge the whole SNBL staff for their precious help during the experiments at the ESRF.

\section{Notes and references}

1 G. Ferey, Chem. Mater., 2001, 13, 3084-3098.

2 S. L. James, Chem. Soc. Rev., 2003, 32, 276-288.
3 J. J. Perry, J. A. Perman and M. J. Zaworotko, Chem. Soc. Rev., 2009, 38, 1400-1417.

4 D. J. Tranchemontagne, J. L. Mendoza-Cortes, M. O'Keeffe and O. M. Yaghi, Chem. Soc. Rev., 2009, 38, 1257-1283.

5 S. T. Meek, J. A. Greathouse and M. D. Allendorf, Adv. Mater., 2011, 23, 249-267.

6 D. Zhao, D. J. Timmons, D. Q. Yuan and H. C. Zhou, Acc. Chem. Res., 2011, 44, 123-133.

7 M. O'Keeffe and O. M. Yaghi, Chem. Rev., 2012, 112, 675-702.

8 N. Stock and S. Biswas, Chem. Rev., 2012, 112, 933-969.

9 T. R. Cook, Y. R. Zheng and P. J. Stang, Chem. Rev., 2013, 113, 734-777.

10 H. Furukawa, K. E. Cordova, M. O'Keeffe and O. M. Yaghi, Science, 2013, 341, 1230444.

11 T. H. Chen, I. Popov, W. Kaveevivitchai and O. S. Miljanic, Chem. Mater., 2014, 26, 4322-4325.

12 V. V. Butova, M. A. Soldatov, A. A. Guda, K. A. Lomachenko and C. Lamberti, Russ. Chem. Rev., 2016, 85, 280-307.

13 Y. J. Cui, B. Li, H. J. He, W. Zhou, B. L. Chen and G. D. Qian, Acc. Chem. Res., 2016, 49, 483-493.

14 A. Schoedel, M. Li, D. Li, M. O'Keeffe and O. M. Yaghi, Chem. Rev., 2016, 116, 12466-12535.

15 T. L. Easun, F. Moreau, Y. Yan, S. H. Yang and M. Schroder, Chem. Soc. Rev., 2017, 46, 239-274.

16 Q. G. Zhai, X. H. Bu, X. Zhao, D. S. Li and P. Y. Feng, Acc. Chem. Res., 2017, 50, 407-417.

17 A. J. Howarth, A. W. Peters, N. A. Vermeulen, T. C. Wang, J. T. Hupp and O. K. Farha, Chem. Mater., 2017, 29, 26-39.

18 J. Lee, O. K. Farha, J. Roberts, K. A. Scheidt, S. T. Nguyen and J. T. Hupp, Chem. Soc. Rev., 2009, 38, 1450-1459.

19 L. Ma, C. Abney and W. Lin, Chem. Soc. Rev., 2009, 38, 1248-1256.

20 M. Yoon, R. Srirambalaji and K. Kim, Chem. Rev., 2012, 112, 1196-1231.

21 K. Lillerud, U. Olsbye and M. Tilset, Top. Catal., 2010, 53, 859-868.

22 A. Corma, M. Iglesias, F. Xamena and F. Sanchez, Chem. - Eur. J., 2010, 16, 9789-9795.

23 C. Prestipino, L. Regli, J. G. Vitillo, F. Bonino, A. Damin, C. Lamberti, A. Zecchina, P. L. Solari, K. O. Kongshaug and S. Bordiga, Chem. Mater., 2006, 18, 1337-1346.

24 E. Borfecchia, S. Maurelli, D. Gianolio, E. Groppo, M. Chiesa, F. Bonino and C. Lamberti, J. Phys. Chem. C, 2012, 116, 19839-19850.

25 F. Bonino, S. Chavan, J. G. Vitillo, E. Groppo, G. Agostini, C. Lamberti, P. D. C. Dietzel, C. Prestipino and S. Bordiga, Chem. Mater., 2008, 20, 4957-4968.

26 S. Chavan, J. G. Vitillo, E. Groppo, F. Bonino, C. Lamberti, P. D. C. Dietzel and S. Bordiga, J. Phys. Chem. C, 2009, 113, 3292-3299.

27 S. Chavan, F. Bonino, L. Valenzano, B. Civalleri, C. Lamberti, N. Acerbi, J. H. Cavka, M. Leistner and S. Bordiga, J. Phys. Chem. C, 2013, 117, 15615-15622.

28 S. L. Qiu and G. S. Zhu, Coord. Chem. Rev., 2009, 253, 2891-2911. 
29 Z. Wang and S. M. Cohen, Chem. Soc. Rev., 2009, 38, 1315-1329.

30 H. X. Deng, C. J. Doonan, H. Furukawa, R. B. Ferreira, J. Towne, C. B. Knobler, B. Wang and O. M. Yaghi, Science, 2010, 327, 846-850.

31 B. L. Chen, S. C. Xiang and G. D. Qian, Acc. Chem. Res., 2010, 43, 1115-1124.

32 K. K. Tanabe and S. M. Cohen, Chem. Soc. Rev., 2011, 40, 498-519.

33 S. M. Cohen, Chem. Rev., 2012, 112, 970-1000.

34 F. X. Llabres i Xamena, I. Luz and F. G. Cirujano, in Metal Organic Frameworks as Heterogeneous Catalysts, ed. F. Llabrés i Xamena and J. Gascon, The Royal Society of Chemistry, 2013, pp. 237-267.

35 J. E. Mondloch, O. K. Farha and J. T. Hupp, in Metal organic frameworks as heterogeneous catalysts, ed. F. Llabrés i Xamena and J. Gascon, The Royal Society of Chemistry, Cambridge, 2013, pp. 289-309.

36 A. D. Burrows, in Metal Organic Frameworks as Heterogeneous Catalysts, ed. F. Llabrés i Xamena and J. Gascon, The Royal Society of Chemistry, Cambridge, 2013, pp. 31-75.

37 P. Deria, J. E. Mondloch, O. Karagiaridi, W. Bury, J. T. Hupp and O. K. Farha, Chem. Soc. Rev., 2014, 43, 5896-5912.

38 J. D. Evans, C. J. Sumby and C. J. Doonan, Chem. Soc. Rev., 2014, 43, 5933-5951.

39 W. G. Lu, Z. W. Wei, Z. Y. Gu, T. F. Liu, J. Park, J. Park, J. Tian, M. W. Zhang, Q. Zhang, T. Gentle, M. Bosch and H. C. Zhou, Chem. Soc. Rev., 2014, 43, 5561-5593.

40 B. Y. Li, D. X. Ma, Y. Li, Y. M. Zhang, G. H. Li, Z. Shi, S. H. Feng, M. J. Zaworotko and S. Q. Ma, Chem. Mater., 2016, 28, 4781-4786.

41 A. Zimpel, T. Preiss, R. Roder, H. Engelke, M. Ingrisch, M. Peller, J. O. Radler, E. Wagner, T. Bein, U. Lachelt and S. Wuttke, Chem. Mater., 2016, 28, 3318-3326.

42 J. H. Cavka, S. Jakobsen, U. Olsbye, N. Guillou, C. Lamberti, S. Bordiga and K. P. Lillerud, J. Am. Chem. Soc., 2008, 130, 13850-13851.

43 L. Valenzano, B. Civalleri, S. Chavan, S. Bordiga, M. H. Nilsen, S. Jakobsen, K. P. Lillerud and C. Lamberti, Chem. Mater., 2011, 23, 1700-1718.

44 S. Chavan, J. G. Vitillo, D. Gianolio, O. Zavorotynska, B. Civalleri, S. Jakobsen, M. H. Nilsen, L. Valenzano, C. Lamberti, K. P. Lillerud and S. Bordiga, Phys. Chem. Chem. Phys., 2012, 14, 1614-1626.

45 G. C. Shearer, S. Forselv, S. Chavan, S. Bordiga, K. Mathisen, M. Bjorgen, S. Svelle and K. P. Lillerud, Top. Catal., 2013, 56, 770-782.

46 G. C. Shearer, S. Chavan, J. Ethiraj, J. G. Vitillo, S. Svelle, U. Olsbye, C. Lamberti, S. Bordiga and K. P. Lillerud, Chem. Mater., 2014, 26, 4068-4071.

47 S. Øien, D. Wragg, H. Reinsch, S. Svelle, S. Bordiga, C. Lamberti and K. P. Lillerud, Cryst. Growth Des., 2014, 14, 5370-5372.

48 C. A. Trickett, K. J. Gagnon, S. Lee, F. Gandara, H. B. Burgi and O. M. Yaghi, Angew. Chem., Int. Ed., 2015, 54, 11162-11167.
49 G. C. Shearer, S. Chavan, S. Bordiga, S. Svelle, U. Olsbye and K. P. Lillerud, Chem. Mater., 2016, 28, 3749-3761.

50 G. C. Shearer, J. G. Vitillo, S. Bordiga, S. Svelle, U. Olsbye and K. P. Lillerud, Chem. Mater., 2016, 28, 7190-7193.

51 Y. Bai, Y. B. Dou, L. H. Xie, W. Rutledge, J. R. Li and H. C. Zhou, Chem. Soc. Rev., 2016, 45, 2327-2367.

52 M. G. Goesten, M. F. de Lange, A. I. Olivos-Suarez, A. V. Bavykina, P. Serra-Crespo, C. Krywka, F. M. Bickelhaupt, F. Kapteijn and J. Gascon, Nat. Commun., 2016, 7, 11832.

53 F. Vermoortele, B. Bueken, G. Le Bars, B. Van de Voorde, M. Vandichel, K. Houthoofd, A. Vimont, M. Daturi, M. Waroquier, V. Van Speybroeck, C. Kirschhock and D. E. De Vos, J. Am. Chem. Soc., 2013, 135, 11465-11468.

54 M. Lammert, M. T. Wharmby, S. Smolders, B. Bueken, A. Lieb, K. A. Lomachenko, D. De Vos and N. Stock, Chem. Commun., 2015, 51, 12578-12581.

55 J. Hajek, M. Vandichel, B. Van de Voorde, B. Bueken, D. De Vos, M. Waroquier and V. Van Speybroeck, J. Catal., 2015, 331, 1-12.

56 D. Yang, S. O. Odoh, T. C. Wang, O. K. Farha, J. T. Hupp, C. J. Cramer, L. Gagliardi and B. C. Gates, J. Am. Chem. Soc., 2015, 137, 7391-7396.

57 I. Luz, C. Rosler, K. Epp, F. Xamena and R. A. Fischer, Eur. J. Inorg. Chem., 2015, 3904-3912.

58 V. L. Rechac, F. G. Cirujano, A. Corma and F. Xamena, Eur. J. Inorg. Chem., 2016, 4512-4516.

59 R. Dalapati, B. Sakthivel, A. Dhakshinamoorthy, A. Buragohain, A. Bhunia, C. Janiak and S. Biswas, CrystEngComm, 2016, 18, 7855-7864.

60 P. Hester, S. J. Xu, W. Liang, N. Al-Janabi, R. Vakili, P. Hill, C. A. Muryn, X. B. Chen, P. A. Martin and X. L. Fan, J. Catal., 2016, 340, 85-94.

61 L. G. Ding, B. J. Yao, W. L. Jiang, J. T. Li, Q. J. Fu, Y. A. Li, Z. H. Liu, J. P. Ma and Y. B. Dong, Inorg. Chem., 2017, 56, 2337-2344.

62 S. Øien-Ødegaard, B. Bouchevreau, K. Hylland, L. P. Wu, R. Blom, C. Grande, U. Olsbye, M. Tilset and K. P. Lillerud, Inorg. Chem., 2016, 55, 1986-1991.

63 M. Rimoldi, A. J. Howarth, M. R. DeStefano, L. Lin, S. Goswami, P. Li, J. T. Hupp and O. K. Farha, ACS Catal., 2017, 7, 997-1014.

64 H. Wu, Y. S. Chua, V. Krungleviciute, M. Tyagi, P. Chen, T. Yildirim and W. Zhou, J. Am. Chem. Soc., 2013, 135, 10525-10532.

65 L. Xu, Y. P. Luo, L. Sun, S. Pu, M. Fang, R. X. Yuan and H. B. Du, Dalton Trans., 2016, 45, 8614-8621.

66 D. D. Borges, S. Devautour-Vinot, H. Jobic, J. Ollivier, F. Nouar, R. Semino, T. Devic, C. Serre, F. Paesani and G. Maurin, Angew. Chem., Int. Ed., 2016, 55, 3919-3924.

67 D. D. Borges, R. Semino, S. Devautour-Vinott, H. Jobic, F. Paesani and G. Maurin, Chem. Mater., 2017, 29, 1569-1576.

68 G. W. Peterson, J. J. Mahle, J. B. DeCoste, W. O. Gordon and J. A. Rossin, Angew. Chem., Int. Ed., 2016, 55, 6235-6238.

69 C. H. Wang, X. L. Liu, J. P. Chen and K. Li, Sci. Rep., 2015, 5,10 . 
70 Z. G. Hu, A. Nalaparaju, Y. W. Peng, J. W. Jiang and D. Zhao, Inorg. Chem., 2016, 55, 1134-1141.

71 A. Kronast, S. Eckstein, P. T. Altenbuchner, K. Hindelang, S. I. Vagin and B. Rieger, Chem. - Eur. J., 2016, 22, 12800-12807.

72 S. Castarlenas, C. Tellez and J. Coronas, J. Membr. Sci., 2017, 526, 205-211.

73 I. Stassen, B. Bueken, H. Reinsch, J. F. M. Oudenhoven, D. Wouters, J. Hajek, V. Van Speybroeck, N. Stock, P. M. Vereecken, R. Van Schaijk, D. De Vos and R. Ameloot, Chem. Sci., 2016, 7, 5827-5832.

74 S. Jakobsen, D. Gianolio, D. S. Wragg, M. H. Nilsen, H. Emerich, S. Bordiga, C. Lamberti, U. Olsbye, M. Tilset and K. P. Lillerud, Phys. Rev. B: Condens. Matter Mater. Phys., 2012, 86, 125429.

75 A. E. Platero-Prats, A. Mavrandonakis, L. C. Gallington, Y. Y. Liu, J. T. Hupp, O. K. Farha, C. J. Cramer and K. W. Chapmant, J. Am. Chem. Soc., 2016, 138, 4178-4185.

76 M. Lammert, C. Glissmann and N. Stock, Dalton Trans., 2017, 46, 2425-2429.

77 D. Yang, V. Bernales, T. Islamoglu, O. K. Farha, J. T. Hupp, C. J. Cramer, L. Gagliardi and B. C. Gates, J. Am. Chem. Soc., 2016, 138, 15189-15196.

78 C. Atzori, G. C. Shearer, L. Maschio, B. Civalleri, F. Bonino, C. Lamberti, S. Svelle, K. P. Lillerud and S. Bordiga, J. Phys. Chem. C, 2017, 121, 9312-9324.

79 M. Lammert, C. Glissmann, H. Reinsch and N. Stock, Cryst. Growth Des., 2017, 17, 1125-1131.

80 V. V. Butova, A. P. Budnyk, A. A. Guda, K. A. Lomachenko, A. L. Bugaev, A. V. Soldatov, S. M. Chavan, S. Øien-Ødegaard, U. Olsbye, K. P. Lillerud, C. Atzori, S. Bordiga and C. Lamberti, Cryst. Growth Des., 2017, 17, DOI: 10.1021/ acs.cgd.1027b00892.

81 M. Kandiah, M. H. Nilsen, S. Usseglio, S. Jakobsen, U. Olsbye, M. Tilset, C. Larabi, E. A. Quadrelli, F. Bonino and K. P. Lillerud, Chem. Mater., 2010, 22, 6632-6640.

82 S. J. Garibay and S. M. Cohen, Chem. Commun., 2010, 46, 7700-7702.

83 M. J. Katz, Z. J. Brown, Y. J. Colon, P. W. Siu, K. A. Scheidt, R. Q. Snurr, J. T. Hupp and O. K. Farha, Chem. Commun., 2013, 49, 9449-9451.

84 C. Kutzscher, G. Nickerl, I. Senkovska, V. Bon and S. Kaskel, Chem. Mater., 2016, 28, 2573-2580.

85 K. T. Hylland, S. Oien-Odegaard, K. P. Lillerud and M. Tilset, Synlett, 2015, 1480-1485.

86 N. C. Thacker, P. Ji, Z. Lin, A. Urban and W. Lin, Faraday Discuss., 2017, 201, 303-315.

87 M. I. Gonzalez, J. Oktawiec and J. R. Long, Faraday Discuss., 2017, 201, 351-367.

88 Y. Y. Liu, K. Leus, T. Bogaerts, K. Hemelsoet, E. Bruneel, V. Van Speybroeck and P. Van Der Voort, ChemCatChem, 2013, 5, 3657-3664.

89 P. Valvekens, E. D. Bloch, J. R. Long, R. Ameloot and D. E. De Vos, Catal. Today, 2015, 246, 55-59.

90 T. Toyao, K. Miyahara, M. Fujiwaki, T. H. Kim, S. Dohshi, Y. Horiuchi and M. Matsuoka, J. Phys. Chem. C, 2015, 119, 8131-8137.
91 L. Braglia, E. Borfecchia, L. Maddalena, S. Øien, K. A. Lomachenko, A. L. Bugaev, S. Bordiga, A. V. Soldatov, K. P. Lillerud and C. Lamberti, Catal. Today, 2017, 283, 89-103.

92 L. Braglia, E. Borfecchia, K. A. Lomachenko, A. L. Bugaev, A. A. Guda, A. V. Soldatov, B. T. L. Bleken, S. Oien, U. Olsbye, K. P. Lillerud, S. Bordiga, G. Agostini, M. Manzoli and C. Lamberti, Faraday Discuss., 2017, 201, 277-298.

93 C. Wang, Z. G. Xie, K. E. deKrafft and W. L. Lin, J. Am. Chem. Soc., 2011, 133, 13445-13454.

94 C. H. Hendon, J. Bonnefoy, E. A. Quadrelli, J. Canivet, M. B. Chambers, G. Rousse, A. Walsh, M. Fontecave and C. Mellot-Draznieks, Chem. - Eur. J., 2016, 22, 3713-3718.

95 L. Braglia, E. Borfecchia, K. Lomachenko, S. Øien, K. Lillerud and C. Lamberti, J. Phys.: Conf. Ser., 2016, 712, 012053.

96 H. H. Fei and S. M. Cohen, Chem. Commun., 2014, 50, 4810-4812.

97 T. H. Zhou, Y. H. Du, A. Borgna, J. D. Hong, Y. B. Wang, J. Y. Han, W. Zhang and R. Xu, Energy Environ. Sci., 2013, 6, 3229-3234.

98 S. Øien, G. Agostini, S. Svelle, E. Borfecchia, K. A. Lomachenko, L. Mino, E. Gallo, S. Bordiga, U. Olsbye, K. P. Lillerud and C. Lamberti, Chem. Mater., 2015, 27, 1042-1056.

99 E. Borfecchia, S. Øien, S. Svelle, L. Mino, L. Braglia, G. Agostini, E. Gallo, K. Lomachenko, S. Bordiga, A. Guda, M. A. Soldatov, A. V. Soldatov, U. Olsbye, K. P. Lillerud and C. Lamberti, J. Phys.: Conf. Ser., 2016, 712, 012125.

100 T. Toyao, M. Saito, S. Dohshi, K. Mochizuki, M. Iwata, H. Higashimura, Y. Horiuchi and M. Matsuoka, Res. Chem. Intermed., 2016, 42, 7679-7688.

101 E. Reddington, A. Sapienza, B. Gurau, R. Viswanathan, S. Sarangapani, E. S. Smotkin and T. E. Mallouk, Science, 1998, 280, 1735-1737.

102 J. Pérez-Ramírez, F. Kapteijn, K. Schöffel and J. A. Moulijn, Appl. Catal., B, 2003, 44, 117-151.

103 R. Kopelent, J. A. van Bokhoven, J. Szlachetko, J. Edebeli, C. Paun, M. Nachtegaal and O. V. Safonova, Angew. Chem., Int. Ed., 2015, 54, 8728-8731.

104 A. T. Bell, Science, 2003, 299, 1688-1691.

105 A. T. Nielsen, J. Org. Chem., 1962, 27, 1998-2001.

106 G. F. Santori, A. G. Moglioni, V. Vetere, G. Y. M. Iglesias, M. L. Casella and O. A. Ferretti, Appl. Catal., A, 2004, 269, 215-223.

107 X.-F. Yang, A. Wang, B. Qiao, J. Li, J. Liu and T. Zhang, Acc. Chem. Res., 2013, 46, 1740-1748.

108 M. Meilikhov, K. Yusenko, D. Esken, S. Turner, G. Van Tendeloo and R. A. Fischer, Eur. J. Inorg. Chem., 2010, 3701-3714.

109 I. Luz, A. Loiudice, D. T. Sun, W. L. Queen and R. Buonsanti, Chem. Mater., 2016, 28, 3839-3849.

110 K. Na, K. M. Choi, O. M. Yaghi and G. A. Somorjai, Nano Lett., 2014, 14, 5979-5983. 
111 A. E. Shilov and G. B. Shul'pin, Chem. Rev., 1997, 97, 2879-2932.

112 R. A. Periana, D. J. Taube, S. Gamble, H. Taube, T. Satoh and H. Fujii, Science, 1998, 280, 560-564.

$113 \mathrm{~J}$. A. Labinger and J. E. Bercaw, Nature, 2002, 417, 507-514.

114 M. Lersch and M. Tilset, Chem. Rev., 2005, 105, 2471-2526.

115 R. Palkovits, M. Antonietti, P. Kuhn, A. Thomas and F. Schüth, Angew. Chem., Int. Ed., 2009, 48, 6909-6912.

116 R. Palkovits, C. von Malotki, M. Baumgarten, K. Mullen, C. Baltes, M. Antonietti, P. Kuhn, J. Weber, A. Thomas and F. Schüth, ChemSusChem, 2010, 3, 277-282.

117 E. S. Gutterød, S. Øien-Ødegaard, K. Bossers, A.-E. Nieuwelink, M. Manzoli, L. Braglia, A. Lazzarini, E. Borfecchia, S. Ahmadigoltapeh, B. Bouchevreau, B. T. Lønstad-Bleken, R. Henry, C. Lamberti, S. Bordiga, B. M. Weckhuysen, K. P. Lillerud and U. Olsbye, Ind. Eng. Chem. Res., 2017, 56, DOI: 10.1021/acs.iecr.1027b01457.

118 A. Schaate, P. Roy, A. Godt, J. Lippke, F. Waltz, M. Wiebcke and P. Behrens, Chem. - Eur. J., 2011, 17, 6643-6651.

119 S. Brunauer, P. H. Emmett and E. Teller, J. Am. Chem. Soc., 1938, 60, 309-319.

120 K. S. W. Sing, in Adsorption by Powders and Porous Solids, ed. F. Rouquerol, J. Rouquerol, K. S. W. Sing, P. Llewellyn and G. Maurin, Academic Press, Oxford, 2nd edn, 2014, pp. 237-268.

121 W. van Beek, O. V. Safonova, G. Wiker and H. Emerich, Phase Transitions, 2011, 84, 726-732.

122 P. M. Abdala, O. V. Safonova, G. Wiker, W. van Beek, H. Emerich, J. A. van Bokhoven, J. Sa, J. Szlachetko and M. Nachtegaal, Chimia, 2012, 66, 699-705.

123 A. L. Bugaev, A. A. Guda, K. A. Lomachenko, V. V. Shapovalov, A. Lazzarini, J. G. Vitillo, L. A. Bugaev, E. Groppo, R. Pellegrini, A. V. Soldatov, J. A. van Bokhoven and C. Lamberti, J. Phys. Chem. C, 2017, 121, 18202-18213.

124 S. Bordiga, E. Groppo, G. Agostini, J. A. van Bokhoven and C. Lamberti, Chem. Rev., 2013, 113, 1736-1850.

125 C. Lamberti, S. Bordiga, F. Bonino, C. Prestipino, G. Berlier, L. Capello, F. D’Acapito, F. X. L. I. Xamena and A. Zecchina, Phys. Chem. Chem. Phys., 2003, 5, 4502-4509.

126 J. Kieffer and J. P. Wright, Powder Diffr., 2013, 28, S339-S350.

127 V. Petř́íček, M. Dušek and L. Palatinus, Z. Kristallog, 2014, 229, 345-352.

128 C. Lamberti, C. Prestipino, S. Bordiga, G. Berlier, G. Spoto, A. Zecchina, A. Laloni, F. La Manna, F. D’Anca, R. Felici, F. D'Acapito and P. Roy, Nucl. Instrum. Methods Phys. Res., Sect. B, 2003, 200, 196-201.

129 T. M. Grehk and P. O. Nilsson, Nucl. Instrum. Methods Phys. Res., Sect. A, 2001, 467, 635-638.

130 S. Carlson, M. Clausen, L. Gridneva, B. Sommarin and C. Svensson, J. Synchrotron Radiat., 2006, 13, 359-364.

131 M. Nachtegaal, O. Müller, C. König and R. Frahm, in X-Ray Absorption and X-Ray Emission Spectroscopy: Theory and Applications, ed. J. A. van Bokhoven and C. Lamberti, John Wiley \& Sons, Chichester (UK), 2016, vol. I, pp. 155-183.
132 B. Ravel and M. Newville, J. Synchrotron Radiat., 2005, 12, 537-541.

133 C. Lamberti, S. Bordiga, D. Arduino, A. Zecchina, F. Geobaldo, G. Spanò, F. Genoni, G. Petrini, A. Carati, F. Villain and G. J. Vlaic, J. Phys. Chem. B, 1998, 102, 6382-6390.

134 S. I. Zabinsky, J. J. Rehr, A. Ankudinov, R. C. Albers and M. J. Eller, Phys. Rev. B: Condens. Matter Mater. Phys., 1995, 52, 2995-3009.

135 M. Newville, J. Synchrotron Radiat., 2001, 8, 322-324.

136 G. Dalba and P. Fornasini, J. Synchrotron Radiat., 1997, 4, 243-255.

137 A. Einstein, Ann. Phys., 1907, 22, 180-190.

138 A. P. Menushenkov, S. Benazeth, J. Purans, A. Y. Ignatov and K. V. Klementev, Phys. C, 1997, 277, 257-264.

139 N. VanHung and J. J. Rehr, Phys. Rev. B: Condens. Matter Mater. Phys., 1997, 56, 43-46.

140 G. Dalba, P. Fornasini, R. Grisenti and J. Purans, Phys. Rev. Lett., 1999, 82, 4240-4243.

141 P. Ghigna, A. Carollo, G. Flor, L. Malavasi and G. S. Peruga, J. Phys. Chem. B, 2005, 109, 4365-4372.

142 L. L. Araujo, P. Kluth, G. D. M. Azevedo and M. C. Ridgway, Phys. Rev. B: Condens. Matter Mater. Phys., 2006, 74, 184102.

143 C. S. Schnohr, P. Kluth, L. L. Araujo, D. J. Sprouster, A. P. Byrne, G. J. Foran and M. C. Ridgway, Phys. Rev. B: Condens. Matter Mater. Phys., 2009, 79, 195203.

144 D. J. Sprouster, R. Giulian, L. L. Araujo, P. Kluth, B. Johannessen, D. J. Cookson, G. J. Foran and M. C. Ridgway, J. Appl. Phys., 2010, 107, 014313.

145 G. Bunker, Introduction to XAFS A Practical Guide to X-ray Absorption Fine Structure Spectroscopy, Cambridge University Press, Cambridge, 2010.

146 A. Agostini, R. Grisenti, C. Lamberti, A. Piovano and P. Fornasini, J. Phys.: Conf. Ser., 2013, 430, 012031.

147 T. Yokoyama, K. Asakura, Y. Iwasawa and H. Kuroda, J. Phys. Chem., 1989, 93, 8323-8327.

148 H. Kuroda, T. Yokoyama, K. Asakura and Y. Iwasawa, Faraday Discuss., 1991, 92, 189-198.

149 N. Van Hung and J. J. Rehr, Phys. Rev. B: Condens. Matter Mater. Phys., 1997, 56, 43-46.

150 G. W. Stinton and J. S. O. Evans, J. Appl. Crystallogr., 2007, 40, 87-95.

151 G. Agostini, C. Lamberti, L. Palin, M. Milanesio, N. Danilina, B. Xu, M. Janousch and J. A. van Bokhoven, J. Am. Chem. Soc., 2010, 132, 667-678.

152 E. Groppo, C. Prestipino, C. Lamberti, P. Luches, C. Giovanardi and F. Boscherini, J. Phys. Chem. B, 2003, 107, 4597-4606.

153 C. Lamberti, E. Groppo, C. Prestipino, S. Casassa, A. M. Ferrari, C. Pisani, C. Giovanardi, P. Luches, S. Valeri and F. Boscherini, Phys. Rev. Lett., 2003, 91, 046101.

154 L. Salassa, E. Borfecchia, T. Ruiu, C. Garino, D. Gianolio, R. Gobetto, P. J. Sadler, M. Cammarata, M. Wulff and C. Lamberti, Inorg. Chem., 2010, 49, 11240-11248. 
155 G. Agostini, S. Usseglio, E. Groppo, M. J. Uddin, C. Prestipino, S. Bordiga, A. Zecchina, P. L. Solari and C. Lamberti, Chem. Mater., 2009, 21, 1343-1353.

156 S. Pascarelli, F. Boscherini, C. Lamberti and S. Mobilio, Phys. Rev. B: Condens. Matter Mater. Phys., 1997, 56, 1936-1947.

157 G. Agostini, A. Piovano, L. Bertinetti, R. Pellegrini, G. Leofanti, E. Groppo and C. Lamberti, J. Phys. Chem. C, 2014, 118, 4085-4094.

158 A. I. Frenkel, C. W. Hills and R. G. Nuzzo, J. Phys. Chem. B, 2001, 105, 12689-12703.

159 G. Agostini, R. Pellegrini, G. Leofanti, L. Bertinetti, S. Bertarione, E. Groppo, A. Zecchina and C. Lamberti, J. Phys. Chem. C, 2009, 113, 10485-10492.

160 J. E. Huheey, E. A. Keiter and R. L. Keiter, Inorganic Chemistry: Principles of Structure and Reactivity, Harpercollins, College, New-York, 4th edn, 1993.

161 S. Calvin, M. M. Miller, R. Goswami, S.-F. Cheng, S. P. Mulvaney, L. J. Whitman and V. G. Harris, J. Appl. Phys., 2003, 94, 778-783.

162 A. I. Frenkel, A. Yevick, C. Cooper and R. Vasic, in Annual Review of Analytical Chemistry, ed. R. G. Cooks and E. S. Yeung, Annual Reviews, Palo Alto, 2011, vol. 4, pp. 23-39.

163 C. Solliard and M. Flueli, Surf. Sci., 1985, 156, 487-494.

164 A. Pinto, A. R. Pennisi, G. Faraci, G. Dagostino, S. Mobilio and F. Boscherini, Phys. Rev. B: Condens. Matter Mater. Phys., 1995, 51, 5315-5321.
165 W. H. Qi and M. P. Wang, J. Nanopart. Res., 2005, 7, 51-57.

166 G. Smolentsev and A. V. Soldatov, Comput. Mater. Sci., 2007, 39, 569-574.

167 E. R. Malinowski, Factor Analysis in Chemistry, Wiley, Chichester, 3rd edn, 2002.

168 E. R. Malinowski, Anal. Chem., 1977, 49, 612-617.

169 A. Martini, E. Borfecchia, K. A. Lomachenko, I. A. Pankin, C. Negri, G. Berlier, P. Beato, H. Falsig, S. Bordiga and C. Lamberti, Chem. Sci., 2017, 8, 6836-6851.

170 E. R. Malinowski, Factor Analysis in Chemistry, Wiley, 1991.

171 A. Elbergali, J. Nygren and M. Kubista, Anal. Chim. Acta, 1999, 379, 143-158.

172 B. K. Dable and K. S. Booksh, J. Chemom., 2001, 15, 591-613.

173 A. Manceau, M. Marcus and T. Lenoir, J. Synchrotron Radiat., 2014, 21, 1140-1147.

174 K. A. Lomachenko, E. Borfecchia, C. Negri, G. Berlier, C. Lamberti, P. Beato, H. Falsig and S. Bordiga, J. Am. Chem. Soc., 2016, 138, 12025-12028.

175 Y. Tulchinsky, C. H. Hendon, K. A. Lomachenko, E. Borfecchia, B. C. Melot, M. R. Hudson, J. D. Tarver, M. D. Korzynski, A. W. Stubbs, J. J. Kagan, C. Lamberti, C. M. Brown and M. Dinca, J. Am. Chem. Soc., 2017, 139, 5992-5997.

176 C. W. Andersen, E. Borfecchia, M. Bremholm, M. R. V. Jørgensen, P. N. R. Vennestrøm, C. Lamberti, L. F. Lundegaard and B. B. Iversen, Angew. Chem., Int. Ed., 2017, 56, 10367-10372. 